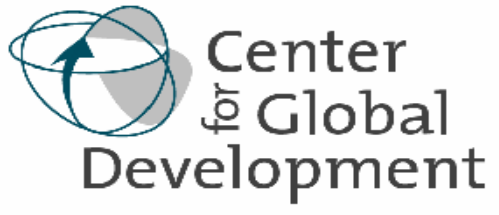

\title{
Do visas kill? Health effects of African health professional emigration By Michael Clemens
}

Abstract
The emigration of highly skilled workers can in theory lower social welfare in the migrant-sending
country. If such workers produce a good whose consumption conveys a positive externality—such as
nurses and doctors in a very poor country—-the loss can be greater, and welfare can even decline
globally. Policies to impede emigration thus have the potential to raise sending-country and global
welfare. This study uses a new database of health worker emigration from Africa to test whether
exogenous decreases in emigration raise the number of domestic health professionals, increase the
mass availability of basic primary care, or improve a range of public health outcomes. It identifies
the effect through two separate natural quasi-experiments arising from the colonial division of the
African continent. These produce exogenous changes in emigration comparable to those that would
result from different immigration policies in principal receiving countries. The results suggest that
Africa's generally low staffing levels and poor public health conditions are the result of factors
entirely unrelated to international movements of health professionals. A simple model proposes that
such results would be explained by segmentation of health workforce labor markets in the sending
countries. The results further suggest that emigration has caused a greater production of health
workers in Africa.

The Center for Global Development is an independent think tank that works to reduce global poverty and inequality through rigorous research and active engagement with the policy community. Use and dissemination of this Working Paper is encouraged, however reproduced copies may not be used for commercial purposes. Further usage is permitted under the terms of the Creative Commons License. This research was generously supported by the John D. and Catherine T. MacArthur Foundation and by the William and Flora Hewlett Foundation. The views expressed in this paper are those of the author and should not be attributed to the directors or funders of the Center for Global Development.

www.cgdev.org 


\title{
Do visas kill?
}

\section{Health effects of African health professional emigration}

\author{
Michael A. Clemens* \\ Center for Global Development
}

March 13, 2007

\begin{abstract}
The emigration of highly skilled workers can in theory lower social welfare in the migrant-sending country. If such workers produce a good whose consumption conveys a positive externality - such as nurses and doctors in a very poor country - the loss can be greater, and welfare can even decline globally. Policies to impede emigration thus have the potential to raise sending-country and global welfare. This study uses a new database of health worker emigration from Africa to test whether exogenous decreases in emigration raise the number of domestic health professionals, increase the mass availability of basic primary care, or improve a range of public health outcomes. It identifies the effect through two separate natural quasi-experiments arising from the colonial division of the African continent. These produce exogenous changes in emigration comparable to those that would result from different immigration policies in principal receiving countries. The results suggest that Africa's generally low staffing levels and poor public health conditions are the result of factors entirely unrelated to international movements of health professionals. A simple model proposes that such results would be explained by segmentation of health workforce labor markets in the sending countries. The results further suggest that emigration has caused a greater production of health workers in Africa.
\end{abstract}

*JEL codes F22, I18, O15. Correspondence to mclemens@cgdev.org. Mailing address: Center for Global Development, 1776 Massachusetts Ave. NW, Suite 301, Washington, DC 20036-1909 USA. Tel. (+1) 202-416-0722, Fax (+1) 202-416-0750. This research was generously supported by the John D. and Catherine T. MacArthur Foundation and by the William and Flora Hewlett Foundation. The opinions expressed here are those of the author alone and do not necessarily reflect those of the Center for Global Development, its board, or its funders. Gunilla Pettersson and Sami Bazzi provided superb research assistance. I would like to thank Alok Bhargava, Nancy Birdsall, Frédéric Docquier, Tamara Fox, Ruth Levine, Prachi Mishra, Todd Moss, Çă̆lar Özden, and seminar participants at MIT, the Northeast Universities Development Conference, the University of the Witswatersrand, and the Sydney G20 summit. Any errors, however, belong to the author. 


\section{Introduction}

Do international borders raise welfare? In what conditions would a benevolent social planner choose less permeable frontiers over more open ones? These questions arguably spawned the field of economics: Hume, Smith, and Ricardo built some of the foundational models of the discipline to ask how much their small island nation should interfere in cross-border goods trade, and The Economist newspaper emerged in 1843 directly from an anti-tariff society. Debates on intervention in other international factor flows - capital and labor-followed, but lost priority after both crashed lastingly after 1914. Only in recent years did both flows regain their belle époque levels worldwide, and the debates are back. Many new proposals to restrict international labor movements arise from a facet of the new upsurge in migration that has no precedent: the international mass migration of highly skilled workers.

When returns to skill were smaller and migration comprised primarily low-skill workers, welfare analysis focused on the destination countries. Those countries remain the focus of the large bulk of migration research. But the shift toward substantial movements of skilled workers has generated a large theoretical and policy literature on the sending-country consequences of migration. Low-income countries need skilled professionals to develop, a common argument goes, and nearly all developing-country governments subsidize professional education in order to reap positive externalities from those engineers' ideas, those lawyers' contracts, those physicians' care. But a thicket of labor and credit market failures prevents them from being paid their marginal social product. If they departed for countries where their private gain better reflects their contribution, they would be lost ("brain drain") and a public good would become a private good ("poaching"). Government intervention would be justified, by this reasoning, to ensure that the positive externality is captured by the country of origin. Warranted public acts would include contractual restrictions on emigration (in self-interested sending countries) and bans on recruitment or tight profession-specific immigration quotas (in altruistic receiving countries).

A related case has been made in the literature on other factor movements. Volumes of theoretical research have argued that subsidies to infant industries raise welfare due to positive scale and network externalities in production. Here, too, the externality raises the possibility that restricting international factor flows can raise welfare; a more impermeable border makes everyone better off. Theory leaves ambiguous the degree and duration of the proper intervention, however, whence a massive empirical literature testing whether in fact countries with borders more impermeable to goods trade are in fact better off. This empirical literature was made possible by data; since 1948 the International Monetary Fund has published detailed annual, bilateral data on international goods trade. 
But no such data have existed for skilled-worker movements, so it has been impossible to test equally plausible hypotheses about the sending-country welfare consequences of international skilled worker movements. There is no place to look up, say, how many physicians or engineers moved from Cameroon to Quebec in 1997, much less how many went from Quebec to Cameroon. This paper makes the question tractable by choosing one region and one profession where welfare consequences of emigration are particularly plausible: African health professionals. It uses a novel database collected for this investigation to test whether or not greater net emigration of such workers, all else equal, reduces sending-country welfare.

It begins with a simple welfare model from which emerge two natural quasi-experiments we can use to test the sending-country welfare consequences of exogenous changes in the permeability of borders to health professional emigration. Both quasi-experiments relate to the colonial division of the African continent. The effects are tested via cross-country regressions, whose use has been much maligned in recent years as being far more convenient than theoretically appropriate to questions such as elucidating the determinants of growth. In the present case, however, cross-country hypothesis testing is precisely the theoretically correct framework. International migration policy is applied exclusively at international borders, so no other unit of analysis besides countries would be meaningful.

The results presented here fail to detect any negative impact of even massive movements of health professionals out of Africa upon health worker stocks, basic primary health care availability, and public health outcomes in African migrant-sending countries. They suggest that the absence of a negative effect of emigration on domestic health worker stocks is plausibly the result of a positive elasticity of labor supply to the expected wage increases afforded by the emigration option. They furthermore suggest that the absence of an effect of emigration on basic primary care availability and public health conditions may be due to the determination of these outcomes primarily by factors unrelated to cross-border movements of health

professionals. These include the geographic and public/private sector distribution of health professionals in the sending country, the skill mix of the health workforce, performance incentives faced by health professionals in the sending country, and the relative importance of primary care versus prevention to the disease burden in Africa.

\section{Academic and policy debates in need of evidence}

General equilibrium models in which the sole market failure is the international border predict large, positive global welfare gains from opening the border (e.g. Hamilton and Whalley 1984; Moses and Letnes 2004; 
Walmsley and Winters 2005). Within the sending countries, the simplest static models predict unambiguous declines in welfare (though always exceeded by gains to migrants). More recent and nuanced models that account for changing returns to other factors, remittances, and other forces predict increased welfare in some sending countries from broad categories of movement comprising all "unskilled" or "skilled" labor collectively.

For decades, however, a strand of strictly theoretical literature has debated whether the migration of certain classes of skilled workers must always decrease sending-country welfare due to a positive local external effect of the exercise of their professions. Grubel and Scott $(1966,1968)$ argued that even the emigration of physicians from developing countries could raise sending-country welfare due to technology transfer, remittances, human capital formation induced by the migration opportunity, and other forces. Aitken (1968) fiercely contested that this "amazing conclusion ... is arrived at only because of an error in [Grubel and Scott's] analysis", positing that large (especially dynamic) external effects mean the welfare of the sendingcountry population must decrease with the departure of each and every physician.

Since then, numerous papers have refined these qualitative theoretical arguments with careful modeling of the relevant externalities (e.g. Miyagiwa 1991). Several have focused on precisely modeling the effect of emigration opportunities on human capital investment (Mountford 1997; Stark et al. 1997, 1998; Beine et al. 2001).

This discussion has been entirely theoretical, with three recent exceptions. Beine et al. (2001) show that aggregate migration rates are correlated with overall schooling in a small cross-section of countries. With greatly improved data, Beine et al. (2003) find a causal effect of emigration among the tertiaryeducated on the sending-country stock of tertiary educated. They produce plausibly exogenous variance in emigration rates using four instrumental variables: sending-country population density, total population, "racial tensions", and the stock of migrants at destination. Finally, Bhargava and Docquier (2006) assemble novel data on physician emigration from 39 African countries and test its causal effect on life expectancy and adult deaths due to AIDS in the sending countries.

That last study differs from the present one in several ways. First, it counts physicians abroad for each African country by an odd blend of country of birth, country of training and country of citizenship. These three measures often give radically different measures of physician outflow, as described in Clemens and Pettersson (2006). Second, and very importantly, its identification strategy allows no way to check for weak instruments - a problem proven capable of generating spurious inference by several recent studies. Third, although it represents a tireless attempt to collect panel data, the majority of the migration data in the panel are not observed but imputed. The African physician stocks reported there occur at five points in time 
for 16 receiving countries, but in 10 of those countries, only one or two timepoints are actually observed; the rest are interpolated. Since migrant stocks are stable over time this amounts to roughly doubling the size of the dataset without adding any new empirical information - artificially shrinking standard errors with a substantial danger of spurious inference. Fourth, that study tests whether or not physician emigration has effects on AIDS deaths without testing the most obvious mechanism of that effect: whether or not physician emigration in fact decreases the number of physicians in the sending country.

Bhargava and Docquier find that the fraction of physicians abroad has a positive and significant effect on the number of adult deaths due to AIDS in general, while-interestingly - it has a negative and significant effect on AIDS deaths in countries where HIV prevalence is low. They also test the effect of the fraction of physicians abroad on life expectancy in the sending country, and find no effect (a positive coefficient statistically indistinguishable from zero).

The present paper extends this literature in two ways. First, it makes a small theoretical contribution by pointing out that the emigration of a health worker does not constitute the loss of a public good to the extent that trained health professionals in the sending country work in a sector with limited external effect (the urban sector, the private health sector, and the non-clinical sector). This subtlety takes on tremendous importance in the least-developed economies, where domestic labor market failures loom large. Second, and more importantly, it assembles novel data to create a simple and transparent empirical test of the welfare effects of an exogenous change in the emigration of African physicians and professional nurses. It uses a single, consistent definition of the emigration rate, a clear and transparent identification strategy, and real observed data.

These debates are not at all purely academic; government policies across the world have arrived well in advance of clear evidence on their effects. On the sending-country side, recent South African legislation has sought to discourage nurse emigration with a combination of punitive licensing measures for emigrants and obligatory in-country service for new graduates. On the receiving country side, in 2001 the United Kingdom's National Health Service progressively banned direct public recruitment of health professionals from all but two developing countries and has pressured private agencies (and other countries) to follow suit. The welfare consequences of these policies in the sending countries remain unknown.

\section{The effects of emigration are theoretically ambiguous}

In Hamilton and Whalley's (1984) classic model of international migration, the elimination of international borders unambiguously results in 1) a smaller labor supply in low-wage areas, 2) lesser welfare in the sending 
country, 3) greater welfare to migrants and receiving countries, and 4) increased global welfare. This section extends that model to incorporate a positive externality from a good produced by the workers who move.

Here that good is "health", and greater average consumption of health increases the incomes of everyone in the country. The marginal social product of health professionals' labor thus exceeds the private product. With restrictive assumptions, increased openness to migration still lowers sending-country welfare but can now actually lower global welfare. Under alternative conditions, the change in sending-country labor supply and welfare - as well as global welfare - can be small or even positive.

\subsection{Demand for health}

\subsubsection{Competitive equilibrium with a positive income externality from health}

A representative agent consumes two goods: $x$ and $h$ ("health"), which generate utility through the Constant Elasticity of Subsitution (CES) function. Suppose that a portion of the agent's income is a linear, separable function of her consumption of health relative to others. If others consume more health than she does, her income goes up; the more the agent's neighbors spend on malaria prevention, for example, the less likely she is to contract the disease and miss work. But if others consume less health than she, her income goes down. In other words income $m=\bar{m}+\eta(\bar{h}-h)$, where $\bar{m}$ is some base level of income, $\bar{h}$ is average consumption of $h$ by other agents, and $\eta \geqslant 0$.

The agent chooses $x, h$ to maximize utility $\left(x^{\alpha}+h^{\alpha}\right)^{1 / \alpha}$ subject to $p_{x} x+p_{h} h=\bar{m}+\eta(\bar{h}-h)$, where $p_{x}, p_{h}$ are prices. The competitive demand function for health is

$$
\widehat{h}=m \widehat{p}_{h}^{\gamma-1}\left(p_{x}^{\gamma}+\widehat{p}_{h}^{\gamma}\right)^{-1}
$$

where $\widehat{p}_{h} \equiv p_{h}+\eta$ is the private cost of health and $\gamma \equiv \frac{\alpha}{\alpha-1}$.

\subsubsection{Social equilibrium with a positive income externality from health}

A planner with a utilitarian social welfare function would set $h=\bar{h}$, so the budget constraint becomes

$p_{x} x+p_{h} h=\bar{m}$. The per capita social demand for health is then $\widetilde{h}=m \widetilde{p}_{h}^{\gamma-1}\left(p_{x}^{\gamma}+\widetilde{p}_{h}^{\gamma}\right)^{-1}$, where $\widetilde{p}_{h} \equiv p_{h}$ is the social cost of health. Note that $\eta>0 \Longrightarrow \widetilde{h}>\widehat{h}$. That is, the positive income externality of health causes agents to consume less health than they would at the Pareto optimum. 


\subsection{Derived demand for health workers}

Health is produced via a CES production function by two inputs, labor $l$ and some other input $z$ so that $h=h(z, l)=\left(a_{z} z^{\delta}+a_{l} l^{\delta}\right)^{1 / \delta}$, where $\varepsilon \equiv \frac{1}{1-\delta}$ is the elasticity of substitution and $a_{z}, a_{l} \geqslant 0$. Health systems choose $z, l$ to maximize $h(z, l)-p_{z} z-w l$ where $p_{z}$ is the price of $z$ and $w$ is the wage to labor in the health sector.The derived per capita demand for labor in the health sector is

$$
l\left(p_{z}, w, h\right)=a_{l}^{\varepsilon} w^{-\varepsilon} h .
$$

Note that $\eta>0 \Longrightarrow l(\widetilde{h})>l(\widehat{h})$, which is to say that fewer than the Pareto optimal number of health workers are employed due to the health externality.

\subsection{Do borders raise the number of health workers?}

\subsubsection{Destination country closed}

There are two countries: the sending country $(s)$ and the receiving country $(r)$. With an impermeable border between them, there are $l_{0}$ health workers per capita - and $L_{0}$ total health workers - in the sending country who receive wage $w^{s}$. Health workers in the receiving country earn $w^{r}$.

\subsubsection{Destination country open, inelastic labor supply}

Suppose now that the border is eliminated so that some health workers in the sending country can sell their labor in the receiving country at a new equilibrium wage $\widehat{w}$. Denote labor demand in the sending country by $l^{d}$, labor supply in the sending country by $l^{s}$, and labor demand in the receiving country by $l^{* d}$. Labor demand by the representative agent in the sending country is governed by $l_{d}=l(\widehat{w}, \widehat{h})$, even though the marginal social product is $l(\widehat{w}, \widetilde{h})$. In the receiving country, health workers are paid their marginal social product.

Migrants supply their labor abroad until the wage at home and abroad equalizes to $\widehat{w}$. Aggregate labor demand in the sending country is $L_{d} \equiv P l_{d}$ and in the receiving country is $L_{d}^{*} \equiv P^{*} l_{d}^{*}$, where $P, P^{*}$ are populations. If $\bar{L}=L_{d}+L_{d}^{*}$ is the (fixed) total number of health workers in the two countries, and by implication the labor supply curve in both countries is assumed vertical, then equilibrium number of health workers in the sending country is

$$
\widehat{L}=\frac{\bar{L}}{1+\frac{P^{*}}{P} \frac{\widetilde{h}}{\widehat{h}}\left(\frac{a_{l}^{*}}{a_{l}}\right)^{\varepsilon}} .
$$


Note that $\widehat{L}$ is strictly increasing in $\widehat{h}$, which is to say that underconsumption of health due to the externality decreases the equilibrium number of workers who remain in the sending country. If wages prior to opening were higher in the receiving country, then unambiguously $\widehat{L}<L_{0}$. Assuming that health workers in the receiving country produce more health $\left(a_{l}^{*}>a_{l}\right)$, then $\partial \widehat{L} / \partial \varepsilon<0$. That is, the more that other inputs to health production can substitute for health workers, the more of them depart.

\subsubsection{Destination country open, elastic labor supply}

Now relax the assumption that labor supply is inelastic in the sending country, and suppose that the opportunity to migrate is allocated randomly. As Stark et al. (1998) and Stark and Wang (2002) point out, skilled workers could make the investment in health worker training based on the expected wage in the sector. This is a weighted average of the sending country wage and the receiving country wage, according to the Harris-Todaro (1970) condition $w_{e} \equiv \phi w_{r}+(1-\phi) w_{s}$. The parameter $\phi$, the fraction of all health workers who emigrate, is defined by

$$
\phi \equiv \psi\left(L_{0}-\widehat{L}\right) / L_{e}
$$

where $L_{0}-\widehat{L}$ is the number of health workers who desire to emigrate, $0 \leqslant \psi \leqslant 1$ is the fraction of those who are permitted to do so, and $L_{e}$ is the equilibrium number of health workers in the sending country based on the expected wage. In the equilibrium governing $L_{e}$, workers' labor is demanded at wage $w_{s}$ but they supply their labor according to the expected wage $w_{e}$ such that

$$
\begin{aligned}
L_{e}^{d} & =a_{1} w_{s}^{-\varepsilon^{d}} \\
L_{e}^{s} & =a_{2} w_{e}^{\varepsilon^{s}},
\end{aligned}
$$

where $\varepsilon^{s}$ and $\varepsilon^{d}$ are the absolute values of the wage elasticity of labor supply and demand. Substituting (4) and the definition of $w_{e}$ into (5) gives a single equation for $L_{e}$ and $\phi$ with no simple closed-form solution for either. But the implicit function theorem (after simplification) yields

$$
\frac{\partial L_{e}}{\partial \phi}=L_{e} \varepsilon_{s}\left(\frac{w_{r}-w_{s}}{\phi w_{r}+(1-\phi)\left(1+\varepsilon_{s} / \varepsilon_{d}\right) w_{s}}\right) .
$$

Note that as long as $w_{r}>w_{s}, \partial L_{e} / \partial \phi>0$. That is, if receiving country wages are higher than those in the sending country, an increase in the fraction who emigrate raises the long-run equilibrium number of health workers in the sending country. It does so by raising the expected wage at any given home wage, or equivalently lowering the home wage that corresponds to a given expected wage - shifting the supply curve down. If the receiving country allows no immigrants $(\phi=0)$ then $(6)$ means that the percent decrease in the 
equilibrium number of health workers in the sending country due to a one percentage point increase in the number who depart is $\left(\partial L_{e} / \partial \phi\right) / L_{e}=\left(\frac{w_{r}}{w_{s}}-1\right) /\left(\frac{1}{\varepsilon_{s}}+\frac{1}{\varepsilon_{d}}\right)$. If this quantity exceeds unity, then starting from autarky, an infinitessimal increase in the number who depart produces a larger increase in the equilibrium number who remain. Rearranging, this condition is

$$
\frac{w_{r}}{w_{s}}-1>\frac{1}{\varepsilon_{s}}+\frac{1}{\varepsilon_{d}}
$$

In a way this restates the result of the preceding section, which showed that if labor is supplied inelastically, increased emigration unambiguously lowers the equilibrium number of health workers in the sending country. That is, (7) must be violated if $\varepsilon_{s}=0$. But if wage gaps $\left(w_{r} / w_{s}\right)$ and labor supply elasticity are sufficiently large, the condition (7) can always be met - the equilibrium quantity of health workers in the sending country rises. Thus:

Proposition 1 If international wage gaps are sufficiently small and labor supply sufficiently inelastic, increased emigration must lower the short-run number of health workers in the sending country and the long-run equilibrium number. Otherwise, increased emigration still lowers the short-run equilibrium number of health workers in the sending country but the long-run equilibrium number can decrease, remain the same, or increase.

\subsection{Do borders raise welfare?}

\subsubsection{One sector}

We have assumed throughout that there is a single sector in which health workers sell their labor in the sending country. Per capita social surplus in the sending country is $s_{1} \equiv \int_{0}^{l}\left(\widetilde{w}(l)-w_{s}\right) d l$ where $\widetilde{w}(l)$ $=a_{l}(\widetilde{h} / l)^{1 / \varepsilon}$ is the inverse social demand function for labor. Thus,

$$
s_{1}=\frac{a \varepsilon \widetilde{h}}{\varepsilon-1} l^{\frac{\varepsilon-1}{\varepsilon}}-l w_{s}
$$

When the health externality $\eta$ is large then $\widetilde{w} \gg w_{s}$ and $s_{1}$ is large and positive, so that the departure of the average health worker unambiguously lowers sending-country welfare. If condition (7) fails and $\widehat{l}<l_{0}$ (openness to emigration lowers the number of health workers in the sending country) then social surplus in the sending country unambiguously declines under openness. The larger the health externality, the greater the decline (since $\left.\partial s_{1} / \partial \eta>0\right)$.

An impermeable border thus raises the welfare of sending-country residents relative to even a partially 
open border. If the social value of health is sufficiently large relative to the private value, the average decline in sending-country welfare due to a departure $\left(s_{1} / l\right)$ can exceed even the private gain to the migrant $\left(w_{r}-w_{s}\right)$, meaning that an impermeable border raises the social surplus of sending country nationals as a whole, not just sending-country residents. Again, by Proposition 1 this is contingent on a decline in the equilibrium number of health workers under openness, which requires sufficiently small international wage gaps and sufficiently inelastic labor supply in the sending countries.

\subsubsection{Two sectors}

Suppose now that the labor market for health professionals in the sending country is segmented into two sectors. In the first sector, health workers are an input to the production of the public good $h$ as before, and private derived labor demand is $l_{1}=a w^{-\varepsilon} \widehat{h}$ even though social demand is higher at $\widetilde{l}_{1}=a w^{-\varepsilon} \tilde{h}$. In the second sector, health workers are an input to the production of a private good $h^{\prime}$ with the same price as $h$, such that $\widehat{h}<h^{\prime} \ll \widetilde{h}$. Consumption of the good $h^{\prime}$ has no positive externality. Derived demand in sector 2 is $l_{2}=a w^{-\varepsilon} h^{\prime}$. Sector 1 might be thought of as the public system of primary health care. Sector 2 might be thought of as the private primary care system or other nonclinical private employment.

Per capita social surplus in the sending country under autarky is now only $s_{2} \equiv \int_{0}^{l_{1}}\left(\widetilde{w}(l)-w_{s}\right) d l+$ $\int_{0}^{l_{2}}\left(w^{\prime}(l)-w_{s}\right) d l$, where $w^{\prime}(l) \equiv a\left(h^{\prime} / l\right)^{1 / \varepsilon}<\widetilde{w}(l)$. Solving gives

$$
s_{2}=\gamma\left(\widetilde{h} \widehat{h}^{\frac{\varepsilon-1}{\varepsilon}}+h^{\prime} \frac{2 \varepsilon-1}{\varepsilon}\right)-l w_{s}
$$

where $\gamma \equiv \frac{\varepsilon-1}{\varepsilon} a^{\frac{2 \varepsilon-1}{\varepsilon}} w_{s}^{1-\varepsilon}$. From (8) and (9) follow three results: 1) $s_{2}<s_{1}$, thus the average social surplus lost when the number of health workers declines by one is less when there is a second domestic sector. 2) $\partial s_{2} / \partial \eta<\partial s_{1} / \partial \eta$, which is to say that when the externality is greater, the average social surplus lost due to the loss of a health worker is lower when there are two sectors. Intuitively, this is because when the externality is larger, workers in sector 1 are paid a smaller fraction of their marginal social product and more choose to work in sector 2 , where they generate a much smaller social surplus. 3) if $\varepsilon$ and $\widetilde{h}$ are sufficiently high, or $a$ and $\widehat{h}$ are sufficiently low, then $\partial s_{2} / \partial \eta<0$. Roughly speaking, if the externality is large and labor demand is elastic, the average social surplus lost from the loss of a health worker declines. This arises from the fact that a larger externality means that each health worker remaining in sector 1 has a larger impact on public health, but fewer health workers supply their labor to sector 1. Under the above conditions, the latter exceeds the former and each emigrating health worker carries a smaller social welfare loss as the externality grows. 
The addition of sector 2 has radically changed the model. When there is one sector, a larger health externality means a greater loss of social surplus due to emigration. But when there are two sectors, all else equal a larger health externality can mean that less social surplus is lost when any given health worker emigrates. In essence the second sector is a 'migration' destination internal to the sending country with greatly diminished social value but enhanced private value to the health worker. Domestic market failures push health workers into this sector, and movement from this sector abroad entails only a small social loss. Thus:

Proposition 2 If health workers in the sending country can sell their labor in a second domestic sector producing a private good that conveys no positive externality, the loss of social surplus from the departure of a representative worker 1) is smaller the larger is the externality of the public good, 2) might arise mostly from lost production of a private good, and 3) is smallest in countries where the health externality is greatest.

This has an important implication. Earlier we saw that when there is a single sector in the sending country and the elasticity of labor supply is sufficiently low, then imposing an impermeable border between the sending country and the receiving country must raise welfare if the health externality is sufficiently large. This reasoning falls apart, however, when either 1) the elasticity of labor supply is sufficiently large, since removing the border can increase the equilbrium stock of health workers, or 2) health workers can produce a private good in a second domestic sector, since the earlier welfare gain from imposing an impermeable border is smaller as the externality in the first sector gets larger. It is easy to envision several extensions to this model. For one, if health workers who emigrate are more likely to be selected from sector 2 than sector 1 , the loss of social surplus from their departure is even smaller.

\subsubsection{A graphical representation}

This can be seen simply in Figure 1. The quantity of health workers in country $s$ is measured from left to right starting at $O_{s}$; the quantity in country $r$ is measured from right to left starting at $O_{r}$. $A B$ is the downward-sloping demand curve for labor in country $r$, where health workers are paid their marginal social product. If health workers in country $s$ are also paid their social product, labor demand in that country is $H A$, and the equilibrium quantity of workers in $r$ and $s$ is $O_{r} L^{*}$ and $O_{s} L^{*}$. If there is a border between the two countries at $L_{0}$, opening the border raises world welfare by the area $A F G$.

But suppose health workers are paid less than their social product in country $s$ (the "sending" country) so that the competitive demand curve for labor there is $B D$. Opening the border still entails the gain $B D F$, but also the social loss $B D G H$; there is not only a loss to the sending country but a net loss to global 
social welfare $B F G H$. Enforcing the border raises collective welfare, despite the harm to migrants and the receiving country. A utilitarian social planner might support policy measures to prevent equilibration from $L_{0}$ to $\widehat{L}$ such as restrictions on recruitment by country $r$ of health professionals in $s$.

But two small refinements might make us doubt this conclusion. First, the diagram has so far assumed a vertical domestic supply curve in both countries. If in fact there is elastic supply of health workers in $s$, following $D I$, opening the border could shift down this supply curve as workers are willing to accept lower wages domestically in exchange for the possibility of migrating to earn the higher wage $w_{r}$. The long-run supply curve shifts out; the short-run curve shifts in. Whether openness increases or decreases the stock of health workers at any given time - and thus whether it lowers sending-country welfare or global welfare - is unclear.

Second, we have assumed so far that there is a single sector in country $s$. Suppose now that health workers within $s$ can choose to work either in sector 1, which produces a good with a positive externality, or sector 2 which does not. The competitive demand curve for labor in sector 1 is $J B$, the social demand curve for labor in sector 1 is $K H$, and the competitive (and social) demand curve for labor in sector 2 is $F B$. Note that the larger is the externality, the lower is $J B$ relative to $K H$, and the fewer workers choose sector 1. Depending on the elasticities, the majority of health workers might be in sector 2 at any given moment, so that the loss of social surplus due to any decline in the aggregate stock of health workers is correspondingly smaller. It is smallest, in fact, in those countries where the health externality is largest. Health workers "drain" out of sector 1 prior to emigration. The welfare effect of international migration becomes small, and more and more of that small effect comes not from the health externality in sector $1(B H K J)$ but from privately captured surplus in sector $2(B E F)$.

Naturally this simplistic, static analysis omits entirely the possibility that part of the welfare gain to migrants $(B C D E)$ could flow back to the sending country in the form of remittances and repatriated savings. It also omits more complex dynamic effects whereby the international circulation of workers could affect domestic health workers' productivity or the demand for health care, both of which could raise sendingcountry welfare.

Under the assumptions above, theory is ambiguous about the magnitudes and even the signs of the effect of relaxed migration policy $(\psi)$ on the stock of health workers in the sending country and social welfare there. We can only reckon the overall effect empirically. A quantitative answer requires three elements: a measure of health professional emigration, a measure of staffing and health outcomes, and some exogenous variance in emigration across different populations. The following three sections discuss each of these in turn. 


\section{An empirical approach}

\subsection{Regression model}

What is the effect of health worker departure from the sending country on the health worker stock of the sending country? A simple regression model to render equation (6) is

$$
\ln \widehat{l}_{i}=\alpha+\theta \ln l_{i}^{\prime}+\eta_{i}
$$

where $\widehat{l}_{i}$ is the stock of health workers per capita in the sending country, and $l_{i}^{\prime}$ is the cumulative number of health workers who have left the receiving country and were health workers at the moment of departure. Suppose we observe only $l_{i}^{*}$, the stock of health workers in the receiving country, per capita in the sending country, such that $l_{i}^{\prime}=c_{i} l_{i}^{*}$ where $c_{i}$ is some country-specific constant. Plugging this into (10) gives

$$
\ln \widehat{l}_{i}=\alpha+\theta \ln l_{i}^{*}+\left\{\eta_{i}+\theta \ln c_{i}\right\}
$$

An OLS estimate of (11) will give biased estimates of $\theta$ to the extent that $l_{i}^{*}$ is correlated with the error term $\left\{\eta_{i}+\theta \ln c_{i}\right\}$. We can reduce this bias by 1) controlling for other factors likely to cause both $l_{i}^{*}$ and $c_{i}$, such as income and conflict, 2) seeking instruments for $l_{i}^{*}$ that are uncorrelated with $\left.\left\{\eta_{i}+\theta \ln c_{i}\right\}, 3\right)$ trying other proxies for $l_{i}^{\prime}$ besides $l_{i}^{*}$, and 4) observing whether inference on $\theta$ is sensitive to exclusion of observations with extreme values of $c_{i}$. The analysis below attempts all of these.

Now suppose that health care availability and health outcomes (both represented by $h_{i}$ ) in the sending country are a function of health workers per capita in the sending country. A simple regression model to render equations (8) and (9) is

$$
h_{i}=h_{0} \widehat{l}_{i}^{\beta} v_{i}\left(l_{i}^{\prime}\right) \Longrightarrow \ln h_{i}=\ln h_{0}+\beta \ln \widehat{l}_{i}+\ln v_{i}\left(l_{i}^{\prime}\right),
$$

where $h_{0}$ is some parameter common to all countries, and $v_{i}\left(l_{i}^{\prime}\right)$ captures some effect of health worker emigration on the quality of health workers in the sending country. Perhaps emigration siphons off the most capable health workers, for example. Alternatively, emigration of health workers from urban areas might pull domestic health workers out of rural areas and into urban areas, diminishing the mass availability of care. Let $v_{i}\left(l_{i}^{\prime}\right) \equiv A_{i}\left(l_{i}^{\prime}\right)^{\delta}=A_{i}\left(c_{i} l_{i}^{*}\right)^{\delta}$, thus

$$
\ln v_{i}=\ln A_{i}+\delta \ln c_{i}+\delta \ln l_{i}^{*} .
$$


Plug (11) and (13) into (12) to get

$$
\ln h_{i}=\left\{\ln h_{0}+\beta \alpha\right\}+(\theta \beta+\delta) \ln l_{i}^{*}+\left\{\ln A_{i}+\beta \eta_{i}+(\theta \beta+\delta) \ln c_{i}\right\}
$$

That is, the effect of health worker departure on health is the sum of a direct effect $\theta \beta$, the degree to which health worker departure lowers the number of health workers in the sending country (10) times the degree to which fewer health workers damage health (12), and an indirect effect $\delta$ capturing effects of departure on the quality of those who remain in the sending country. A regression based on (14) will generate biased estimates of the coefficient $\theta \beta+\delta$ to the degree that the size of the health-worker diaspora $l_{i}^{*}$ is correlated with $\left\{\ln A_{i}+\beta \eta_{i}+(\theta \beta+\delta) \ln c_{i}\right\}$. This bias diminishes if we 1) control for other factors likely to simultaneously cause $l_{i}^{*}, A_{i}, \eta_{i}$, and $\left.c_{i}, 2\right)$ seek instruments for $l_{i}^{*}$ uncorrelated with $\left.\left\{\ln A_{i}+\beta \eta_{i}+(\theta \beta+\delta) \ln c_{i}\right\}, 3\right)$ try other proxies for $l_{i}^{\prime}$ besides $l_{i}^{*}$, and 4 ) observe whether inference on $\theta \beta+\delta$ is sensitive to exclusion of observations with extreme values of $c_{i}$.

Notably, $\widehat{l_{i}}$ is not the right-hand side of (14). More health professionals at home are certainly posited to increase health (through $\eta_{i}$ ). But as health conditions can obviously have a reverse effect on the number of health professionals, this effect is not identified without proper instruments for $\widehat{l_{i}}$, which are not explored in this study. To the extent that the instruments for $l_{i}^{*}$ are valid, however, relegating $\widehat{l_{i}}$ to the error term does not bias the estimate of $\theta \beta+\delta$.

\subsection{Measuring African health worker emigration}

The central reason for the lack of empirical research on the effects of international migration is the absence of a comprehensive database of bilateral international migration flows. Even aggregate flows between most country pairs are unknown, to say nothing of age- or occupation-specific flows. This study required building a novel database of the cumulative net emigration of doctors and nurses from each African country. The database simply counts how many African-born doctors and professional nurses were living and working in each of the nine most important destination countries for skilled African emigrants at the time of the most recent census in the destination country. The receiving countries comprise Australia, Belgium, Canada, France, Portugal, South Africa, Spain, the United Kingdom, and the United States, whose last censuses occurred between 1999 and 2001.

The resulting matrix of 53 sending countries and 9 receiving countries, presented by Clemens and Pettersson (2006), is the first occupation-specific database of skilled-worker net bilateral migration for a large number of developing countries with a consistent definition of what constitutes an "emigrant". These data, 
combined with WHO estimates of the number of doctors and nurses who live and work in each African country, allow easy estimation of the fraction of doctors and nurses from each country who lived and worked abroad in the year 2000. Figure 2 presents these estimates for physicians; Figure 3 does the same for professional nurses. Some considerations are necessary to properly interpret these estimates.

\subsection{What is an 'African' doctor?}

There is no single ideal measure of "African health worker emigration". One can interpret each component of the phrase in multiple ways. Is an "African" someone born in Africa, someone whose ancestors for several generations were born in Africa, someone trained in Africa, or someone who holds African citizenship? Does

"Africa" include North Africa and all of South Africa? Is a "health worker" someone who was trained as such or someone who currently works in the health sector? How long must one stay outside the country to be an "emigrant"?

This analysis classifies "Africans" by country of birth; it includes the entire African continent; it counts as doctors and nurses only those currently employed as doctors and nurses; and it calls "emigrants" those who were residing in each receiving country on a sufficiently permanent basis circa 2000 to be included in that country's most recent census. These choices make the data suitable for the present purpose but less useful for certain other purposes. Take the example of a physician born in Zimbabwe and trained in South Africa who lives in Canada and holds on office job in the pharmaceutical industry. Researchers interested in the incentives faced by young educated people in Zimbabwe might be more interested in her country of birth, while those interested in the fiscal impact of emigration on South Africa might be more interested in her country of training. Those interested in the relationship between migration and Black Economic Empowerment might be more interested in her ethnicity than her country of birth. Those interested in the specifically medical dimension of professional emigration might be interested to know that she was trained as a clinician despite the fact that she does not now work as such.

Most studies that have attempted to measure African phyisician emigration previously have primarily or exclusively classified 'emigrants' according to their country of training (Hagopian et al. 2004; Mullan 2005; Bhargava and Docquier 2006; WHO 2006, p. 100). But this is not the single or even the most accurate measure of professional emigration. This approach would lead to decent statistics for a study of, say, the fiscal consequences of physician emigration; the vast majority of African-trained doctors are trained with public funds. (It would be problematic even for this purpose, however, since a portion of African doctors trained abroad do so using scholarships funded by their home governments.) But a narrow focus on country 
of training would not be appropriate for other studies - such as an investigation of the effects of physician emigration on health system staffing, health care availability, or health outcomes in the countries of origin.

To see this, note that 12 of the 53 countries in Africa (and 11 of 48 Sub-Saharan countries) do not have a medical school accredited by the Foundation for Advancement of International Medical Education and Research, or FAIMER (Educational Commission for Foreign Medical Graduates 2007). A medical degree from a FAIMER-accredited school is a prerequisite to licensure in major receiving countries such as the United States (American Medical Association 2007), and related but effectively similar restrictions apply in Australia and Canada. This means that, properly measured, an indicator of physician 'drain' based strictly on country of training would define about a quarter of Sub-Saharan Africa to have lost zero physicians to emigration. It is certain, however, that physicians would have left most or all of those countries to some degree at some point, with possible consequences for staffing, the availability of care or health outcomes. For related reasons, a country-of-training based measure would artificially define nurse emigration from most Francophone African countries to be extremely small, since French law currently mandates that only graduates from French nursing schools may practice as professional nurses in France. Home-trained nurses who leave must therefore train again, in France, in order to appear in the data as practicing nurses in Franceso they become foreign-trained nurses. Beyond this, a country-of-training measure for either doctors or nurses would give an odd accounting even for countries that do have accredited schools but many of whose nationals nevertheless train in other African countries. For instance: Doctors in the UK who were born in Zambia and Zimbabwe, but who trained in South Africa, would contribute exclusively to the South African 'brain drain'-a classification that might be sensible for some research questions, but not others.

Certainly a country-of-birth measure is problematic in that includes people who may have become health professionals after emigration (and may not have become health professionals had they stayed). But a measure based strictly on country of training is also highly problematic. The literature must make progress on rigorous definition of what constitutes a skilled emigrant. This study simply uses both approaches and observes that the definition does not affect the findings here.

As this literature advances, we must avoid mixing the different classifications. In Bhargava and Docquier (2006), African physicians abroad are counted in some destination countries by their country of birth, in others by their country of citizenship, and in others by their country of training. This fact renders the blended database extremely problematic. To give one example, the French Ordre National des Médecins reports that in 1999 there were 238 physicians in France who were citizens of Sub-Saharan African countries, but the French census of 1999 reports 4,203 physicians in France who were born in Sub-Saharan Africa-a 
difference of 1,766\%! To make another comparison, in 2001 the Canadian Medical Association reports 190 physicians in Canada trained in Egypt, but the census of the same year shows 750 Egyptian-born physicians (a 395\% difference). Such discrepancies are the rule, not the exception. Clearly, mixing these different classifications can destroy the ability of the resulting number to measure anything at all. It is imperative to choose a single definition of "emigrant" and retain it.

The case of Mozambique further illustrates the sensitivity of data like these to different assumptions. The Mozambique Medical Association estimates that only around 5\% of Mozambican physicians work abroad. Destination-country census data show that about $75 \%$ of people born in Mozambique who now work as physicians do not live in Mozambique. The main cause of this disparity is the fact that many of those physicians are of European ancestry and departed in the mass exodus of Portuguese colonists around independence in 1975. But it is not at all obvious that counting whites results in a poor measure of human capital loss. In South Africa white health professionals today play an important role in educating a new generation of black health professionals. It is true that Mozambican-born physicians in the white colonist class were providing most of their health care to urban elites in the colonial era rather than to rural blacks, but the same could be said of many black physicians in today's independent African states.

\subsection{Nine destination countries proxy for the world}

This analysis also relies on the assumption that counting how many African health professionals live and work in the nine most important destination countries gives an excellent proxy for how many live and work in any foreign country. Those nine countries are the United Kingdom, United States, France, Australia, Canada, Portugal, Belgium, Spain, and South Africa. I selected these seeking a balance between coverage and the time and expense of additional data collection.

The primary reason that using these destination countries gives a good proxy for total health professional emigration is that the first eight receiving countries alone account for $94.2 \%$ of all African-born, universityeducated people residing in any OECD country in 2000. ${ }^{1}$ My experience comparing the migration patterns of African health professionals to those of other types of well-educated migrants suggests that the proportion of total African health professional emigrants is similar to this value. I add a ninth country, South Africa, because I take it to be the most important non-OECD receiving country for African health professionals. Previous datasets that have focused on a single receiving country, such as that of Hagopian and others (2004), do not give a full picture of emigration rates by sending country since bilateral flows vary greatly across sending countries.

\footnotetext{
${ }^{1}$ Calculated using the census data from Dumont and Lemaître (2005).
} 
It is of course possible that another non-OECD country, such as Saudi Arabia, is important for some countries, or that health professionals differ greatly in their migration patterns from other skilled professionals. But survey data from African health professionals considering emigration suggest that neither of these is the case. Between 2001 and 2002, the World Health Organization interviewed 2,382 doctors, nurses, and other health professionals in six African countries (Awases et al. 2004, p. 38). Each person declaring an intention to emigrate was asked his or her favored destination. The fraction of these in each country who gave one of our nine destination countries was $89.3 \%$ in Cameroon, $91.8 \%$ in Senegal, and $94.6 \%$ in South Africa. A small percentage of respondents in Zimbabwe mentioned Botswana and New Zealand as destinations but the vast majority mentioned one of our nine receiving countries. Respondents from Ghana and Uganda did not mention any countries outside Africa besides the US and UK, and these two destinations plus South Africa accounted for the vast majority of favored destinations in both cases.

Oosthuizen (2005, p. 177) surveyed in 2002 the favored destination countries of a sample of Registered Nurses in South Africa who had just finished their training if they were to work outside South Africa. Of these, $24 \%$ mentioned countries outside Africa not included in the nine considered here: Ireland (2\%), New Zealand (4\%), and Saudi Arabia (18\%). An additional 11\% mentioned unspecified "other countries in Europe and Africa", a subset of which may be included in the nine countries considered here. These results are somewhat difficult to interpret since, of the 105 people who answered the survey, only 85 stated that they would ever consider working outside the country while 91 gave a favored destination if they were to work outside the country. The 105 respondents were self-selected from a pool of 500 inititally contacted, so nonresponse bias in these numbers is a real possibility. Note also that direct recruitment of nurses by Saudi Arabia in South Africa is a very recent phenomenon, meaning that the proportion of emigrating South African Registered Nurses who went to Saudi Arabia before the year 2000 is certainly much lower than $18 \%$.

Both in the surveys of Awases et al. and of Oosthuizen a small fraction of emigrating African health professionals reveal the intent to work in another African country, a flow which is not captured by the data presented here and which represents a small discrepancy between these numbers and true emigration to all other countries. It is smaller still when one considers reciprocal flows: A small number of emigrating Nigerian physicians go to work in Ghana, but a small number of emigrating Ghanaian physicians go to work in Nigeria. Counting each as an additional loss would ignore the fact that for intra-Africa movements, one country's loss is another's gain. And this discrepancy, to the extent that it is small and largely independent of country characteristics, contributes primarily white noise to the data here rather than any bias that would affect the analysis. In sum, the true number of health professionals working abroad may exceed the number working in the nine destination countries focused on here by an amount on the order of $5-10 \%$. 


\subsection{Measuring outcomes}

So much for the independent variable. Measuring the quantity of health workers per capita in different African countries, on the left hand side of equations (6) and (11), is relatively simple. Decent statistics can be had from the World Health Organization's Global Health Atlas. Though surely including some measurement error that is occasionally substantial, such error is in the dependent variable and probably not so far from classical that it biases the coefficient estimates.

More challenging is to measure "welfare" in equation (6) or "health" in equation (14). This study proxies for these unobservables with a range of indicators of the mass availability of primary health care and of basic public health conditions. Certainly several other indicators could be used, such as the availability of specialized tertiary care or mortality due to a specific medical condition whose incidence is limited relative to the greater population. The decision of which indicators to use was primarily a function of policy relevance; policy discussions of medical migration focus on its effects upon countries where generalized health conditions are so dire, not on its effects upon the availability of cancer treatment. An ancillary reason is that no international organization publishes country-by-country data on the availability of tertiary care for conditions like cancer, heart disease, or diabetes in Africa.

\section{Simple correlations}

\subsection{Correlation of health worker stocks abroad and at home}

The indicator of staffing impact used here is therefore the total number of physicians or professional nurses in the country in the year 2000 as reported by the World Health Organization. Staffing effects might well be measured by other metrics, such as the degree of rationing in the health worker labor market (vacancy rates) or shifts in the domestic geographic distribution of professionals. But the model makes clear that at a minimum, if emigration constrains staffing in the health system as a whole it should decrease the total number of health professionals in the country.

Figure 4 plots domestic physicians against physicians working abroad, each expressed per capita of the sending country, for all 53 African countries. The simple correlation is unmistakably positive.

A correlation of this kind establishes little about the absolute magnitude of any particular pathway of causation between the two variables. But it does contain a great deal of information about the relative magnitudes of different causal forces at play on the continent. In Figure 2 we observe tremendous variation 
in the tendency for physicians to leave different African countries, and in Figure 4 we are faced with the simple fact that even these massive movements have been powerless to strip the most affected countries of their physicians. The negative impact on physician stock due to emigration, an accounting identity, is obviously only one of several interacting causal forces determining this net positive correlation. There are only three possibilities: Either greater domestic physician stocks must be driving greater emigration, or greater emigration must somehow be encouraging the expansion of domestic physician stocks, or unobserved country charactertistics must be simultaneously encouraging both expanded physician emigration and expanded domestic physician stocks (or some combiation of these).

The next section will attempt to distinguish among those forces. But even before entering that discussion, one thing is clear: Whichever of these three other forces is at work, it or they utterly overwhelm the accounting-identity "drain" of physicians via emigration as a determinant of domestic physician staffing. Put differently, even the simple correlation of Figure 4 makes clear that if one is interested in knowing why physician staffing is low across the entire health system of a particular African country, one learns little from counting how many physicians have left that country. The primary causes of staffing constraints clearly lie elsewhere. The below discussion of Table 3 makes clear that the emigration of professional nurses likewise has a strong positive correlation with domestic nurse stocks; the same reasoning applies also to them.

\subsection{Correlation of health worker stocks abroad with public health outcomes at home}

Likewise one can think of various measures of health care or health outcomes that might be affected by the departure of health professionals. Advanced tertiary care might be affected, such as intensive care for newborns or cardiac surgery, as might basic primary care for malaria and diarrhea. Since the migration literature commonly refers to rich countries' admission of emigrant health professionals as "poaching" — which I define as the appropriation of a public good for private gain-I focus here on public health impacts. If physician and nurse emigration adversely affects treatment options for the masses of low-income people in African countries its effects should be seen in broad public health indicators. These might include the mortality rate under age five, the fraction of births attended by trained health personnel, and the fraction of persons with HIV receiving modern treatment.

This is not to deny the importance of tertiary care. But the marginal utility of those receiving advanced tertiary care in Africa, elites in their great majority, arguably does not differ greatly from the marginal utility of tertiary care to the middle classes of rich countries. If there is to be a global welfare loss from 
shifting health care from poor to rich countries, then, it is likely to be found in the basic primary care whose marginal utility to low-income Africans is high.

Figure 5 plots the stock of physicians abroad against what is perhaps the fundamental indicator of health conditions in the mass of low-income people: the mortality rate under age 5, per 1,000 live births. Children do not appear to be markedly healthier in Niger, where very few physicians have left, than in Ghana, where the majority have left.

Again, this says very little about the absolute magnitude of causation from physician emigration to public health conditions among the poor. A small increase in child mortality due to physician emigration is compatible with the simple negative correlation of Figure 5 provided there are other, confounding forces. But it does suggest that any such effect is utterly swamped by the other pathways of causation. Once again, there are only three possible confounding effects: Either lower child mortality somehow causes greater physician emigration, or greater emigration must somehow cause lower child mortality, or unobserved country charactertistics must be simultaneously encouraging both expanded physician emigration and lower child mortality (or some combiation of these). The section to follow explores this issue. But without going any further, Figure 5 makes it clear that if we want to know why low-income children are dying in a particular African country, we learn nothing from counting how many physicians have emigrated. The discussion of Table 5, to follow, demonstrates that all of these arguments apply equally to professional nurses.

\section{Measuring the effects with natural quasi-experiments}

Proposition 1 suggests that an exogenous change in openness to emigration can either raise or lower the equilibrium domestic number of health professionals, depending among other things on the elasticity of labor supply. Proposition 2 implies that the same change can raise welfare if the number of health professionals rises, and if the number falls, openness can lower welfare to an arbitrarily small degree depending on the structure of the domestic labor market. In short, the staffing and welfare effects of an exogenous change in openness to emigration are empirical questions.

Simple correlations show that if there is any negative, causal effect of emigration on health and staffing, it is small relative to the other forces shaping these variables. But we might also be interested in learning the magnitude of the causal effect, and the right natural experiment could help isolate and measure it. Another reason to seek an exogenous driver of migration is that it will correct for attenuation bias due to measurement error in the emigration variable. There is little reason to expect that physician counts by country of birth are 
measured with any substantial error by receiving-country governments, but perhaps measuring emigration by country of birth is a measurement with error of some other emigration indicator that most affects health and staffing.

The simple model above directly yields two candidates for plausibly exogenous instruments. Note that equations (2) and (3) imply that $\partial \phi / \partial \psi>0$ and $\partial \phi / \partial\left(P^{*} / P\right)>0$. In other words:

Proposition 3 When immigration policy is more open in the receiving country a larger fraction of the sending-country health workforce departs. Likewise, when the receiving country is large relative to the sending country, a larger fraction of the sending-country health workforce departs.

All else equal, then, sending-country size should negatively affect emigration; receiving-country size should positively affect emigration. There is little reason to think that either has a substantial direct effect on health. Sending-country size has been used as an instrument for emigration by Beine et al. (2003). But African history allows us to gain further identification from the fact that some emigrants are exogenously channeled to some receiving countries.

\subsection{Two natural experiments arising from the colonial division of the continent}

European colonial interventions in the 18th and 19th centuries largely fixed the modern international frontiers of Africa. But different European powers did not use markedly different criteria in selecting the locations of initial outpost settlements. And when the interior of the continent was carved up in a series of conferences, disputes, and treaties in the years leading up to 1900, "boundaries were completely artificial: heterogeneous tribes were lumped together, while watersheds and meridians cut some tribes asunder" (McEwan 1968, 214). Whether any given doctor in the middle Niger River valley grew up in tiny Benin speaking French or in giant Nigeria speaking English has little to do with her personal traits or with local health conditions. But there are several reasons to believe that her country affects her propensity to emigrate. The two most important are the language of training (which affects professional opportunities abroad) and the size of her country (which affects professional opportunities at home).

I argue here that neither of these is likely to directly affect health system staffing levels, basic primary health care, or basic public health outcomes. To the extent that this is true, language and country size create exogenous variance in emigration rates, and are valid instruments for emigration rates in the regressions that follow. Said differently, variance in African countries' dominant languages and sizes constitute two natural quasi-experiments permitting estimation of the causal effect of emigration on staffing, basic care, and public health. 


\subsubsection{Linguistic heritage}

For reasons having little to do with their economic conditions, geography, culture, or skill, a large fraction of African health professionals are trained in French and a different, large fraction is trained in English. If this historical accident substantially affects emigration rates, then, francophonie might serve as a valid instrument in regressions seeking the determinants of health professional staffing and health outcomes.

Assume for a moment that the ability of any given African health professional to obtain a job in one of the principal destination countries is a function solely of the availability of positions. An African physician considering employment abroad could join a labor market of approximately 210,000 physician jobs in France and Francophone Canada, or a market of about 860,000 physician jobs in the United States, United Kingdom, Australia, and Anglophone Canada. Assume further that the fraction of positions that are available at any given time is roughly similar across destinations. Since a major part of the immigration barrier in all of these countries is a rigorous language requirement, this suggests that all else equal, an English-speaking African emigrant physician has about four times the job opportunities abroad. For professional nurses, the major Francophone destinations hold about 470,000 jobs whereas the major Anglophone destinations hold about 3.2 million. English-speaking African professional nurses, then, have roughly six to seven times the number of job opportunities abroad.

But of course the availability of positions is not the only barrier. Relaxing this assumption we see that the difference in opportunities abroad is even more pronounced between Francophone and Anglophone countries. In addition to the language requirement, several other barriers vary across destinations: Notably licensing requirements are somewhat more relaxed in Anglophone than in Francophone countries, for both doctors and nurses. Newly-arrived physicians trained in Africa who wish to practice in France must repeat the process of medical residency, practicing under supervision for three years, before becoming licensed for independent practice. Few exceptions are granted. In the United Kingdom, in contrast, somewhere between three months and three years of supervised practice are required, decided ad hoc by General Medical Council. In Australia between one and three years are required - decided on an individual basis and varying across states - but this requirement can be waived for those willing to practice in rural "areas of need". In Canada, general practitioners are required to practice under supervision for two or three years, though again waivers are granted by some provinces for those practicing in "under serviced" rural areas. The United States requires three years of supervised practice with few exceptions, but "J1" training visa policy makes it easier for physicians to stay in the country for work following residency for those who will work in rural "Medically Underserved Areas". 
The general picture that emerges is that France's licensure requirements for foreign physicians are somewhat more stringent than those of the other major destination countries for African physicians, both de jure and de facto. This may contribute to the fact that, if one omits exceptional Algeria, Morocco, and Tunisia from the sample, African-born physicians make up about $2.4 \%$ of the physician workforce in France but $3.9 \%$ of the workforce in the United Kingdom, United States, Australia and Canada collectively.

For nurses there is an even clearer difference in licensure requirements. African-trained nurses wishing to practice in France must first, regardless of their current qualifications and experience, enroll in and graduate from a French nursing school to earn the diplôme d'état. This is in sharp contrast with the major Anglophone destination countries (and Francophone Canada), for which it sufficies to pass a language and skills test and provide a transcript of prior training credential. This differential barrier only substantially affects those who are foreign-trained (who constitute, in the US for example, a minority of all African-born professional nurses). But it is likely one reason why-again omitting exceptional Algeria, Morocco, and Tunisia-African-born professional nurses make up about $1.1 \%$ of the professional nurse workforce in France but $1.4 \%$ in the major Anglophone destinations collectively.

Not only, then, are there more opportunties abroad for English-speaking African health professionals, but those opportunities are more easily accessible. One might expect, then, that emigration rates for both physicians and nurses are substantially higher in Anglophone than Francophone countries, and below we will see that this is indeed the case. But francophonie is not a valid instrument in regressions determining staffing or health outcomes unless it has no effect on these through other channels than migration.

Colonial affiliation might directly affect staffing and health in two ways: one arising from where different colonial powers chose to settle, another from how they ran their colonies. Different colonial powers might have chosen which parts of Africa to colonize according to local traits likely to affect today's staffing and health. They might also have run their colonies in ways whose differences generated systematic differences in today's staffing and health.

There is little evidence that colonists' initial coastal settlements or the subsequent partition of the interior took place according to criteria of development potential, natives' characteristics, or reigning disease conditions. Historians are clear that at the time of settlement and partition, "there was little or no exact knowledge of the resources available in Africa or of the problems which might be involved in developing them profitably" (Fage 1978, 321). "Statesmen and diplomats met in offices or country houses and drew lines across maps which themselves were usually inaccurate" (Oliver and Fage 1963, 189). "The final division of territories reflected not so much the strength of European interests on the ground as the political power 
of the claimants in Europe" (Oliver and Atmore 2005, 129). After partition, the European powers "had few specific plans about what to do with them. Much had been acquired simply for the purpose of keeping other powers out. Specific possibilities suggested the development of gold mining here, cotton growing there ... but long-range plans for economic, social, or political change were very few indeed" (Curtin et al. 1978, $472-3)$.

To be sure, each European power was motivated partly by the economic potential of the coloniesalongside more prominent motives of national prestige, military strategy, evangelism, and diplomatic advantage (Sanderson 1985, 116; Gann 1969, 113-119). And borders were sometimes drawn with regard to intact African polities; the border between Nigeria and French West Africa was set partly in accordance with preexisting tribal territories, as was that between Angola and Rhodesia (Touval 1966, 289). But these motives did not differ systematically accross different European powers. Sanderson (1985, 105-6) flatly concludes that "no economic model can explain, even in the broadest and most general terms, the pattern of partition that actually took place."

It is nevertheless true that, simply by chance rather than design, French-speaking settlers may have ended up in regions that are naturally more prone to disease. Many Francophone countries cluster close to the equator not far from the Gulf of Guinea, where tropical diseases are more prevalent than at other latitudes. Public health outcomes may then be materially different in Francophone countries - though this would not affect regressions whose dependent variable measures treatment effort or domestic supply of professionals. Empirically, however, the non-Francophone countries are almost as tropical as the Francophone. A simple cross-country average of the fraction population living in the tropics, for example, is 0.85 for Francophone Africa and 0.80 for non-Francophone (Gallup et al. 1998).

The other way in which colonial affiliation could directly affect staffing or health is through different powers' differing treatment of the colonies after partition. La Porta et al. (1997) show that countries with French civil law have weaker investor protections than others and less-developed capital markets. Francophone countries may thereby have poorer general economic conditions and more difficult business conditions for health professionals. Furthermore, Francophone and Anglophone educational systems differ substantially, in ways that could theoretically affect the quantity or quality of health care professionals, with possible consequences for treatment and health outcomes as well.

Empirically, however, these theoretical concerns do not provide a strong case for nonexcludability of the Francophone instrument in the regressions to follow. First, the p-value of a t-test of the null hypothesis that mean income per capita is equal between Francophone (mean 714) and non-Francophone countries (mean 
1143 ) is 0.28 , failing to reject the null. The non-Francophone mean falls to 934 and the p-value is 0.46 if one excludes the Seychelles from the sample. Nevertheless, to be on the safe side, all regressions using Francophone as an instrument include income per capita to account for systematic differences in general economic conditions between Francophone and non-Francophone countries. Second, achievements of higher education in the two groups of countries do not greatly differ. The fraction of the population over age 15 who has completed tertiary education in Francophone African countries (1.1\%) is very similar to the fraction in non-Francophone (1.0\%) (Barro and Lee 2000). To be conservative here, we nevertheless include a basic measure of the strength of the educational system - gross primary school enrollment - to all regressions that use francophonie as an instrument.

\subsubsection{Country size}

It is a well-known theoretical and empirical result that smaller countries are more open to trade (e.g. Alesina et al. 2005; Rose 2006). Country size has been exploited as a valid instrument for trade (e.g. Frankel and Romer 1999). The same models with insubstantial changes predict that smaller countries will be more open to international movements of people as well — for the same reasons of economies of scale in input and output markets and in complementary goods and services. Docquier and Rapoport (2004) document that net emigration rates per capita in the sending country do decrease monotonically with sending country size, so that aggregate emigration rates are less than a fifth in countries with population over 25 million of what they are in countries under 4 million. Docquier and Marfouk (2005, p. 19) note the empirical regularity that emigration rates are higher, all else equal, in smaller countries, and that "these differences cannot be attributed to the educational structure of residents or to a stronger selection in migration flows. Smaller countries simply tend to be more opened to migration."

This should hold a fortiori for skilled worker migration, since one might expect greater economies of scale in production inputs complementary to high-skill workers than low-skill. Intuitively, imagine taking any single country on earth and randomly chopping it into multiple smaller countries of different sizes. Since economies of scale are greater for hospitals than for primary schools, this would result in greater rates of labor "migration" across the new borders by hospital workers than by primary school teachers. The largest of the new mini-countries would be much more likely to contain more hospitals per capita than the smallest minicountries, but not substantially more likely to have more primary schools per capita. Labor "emigration" from the largest mini-countries would thus be lower among relatively high-skill surgeons who work at the hospitals than among relatively low-skill primary school teachers, simply because hospitals must be few and large to work properly. 
These complementary goods and services are more available in larger African countries. A good proxy for the availability of complementary goods and services for health professionals in a country is the existence of an internationally accredited medical school in that country. Sustained operation of an internationalclass medical school requires myriad goods and services complementary to the profession. Hagopian et al. (2004) catalog the number of medical schools in each African country accredited by the Foundation for the Advancement of International Medical Education and Research (FAIMER). All 11 African countries with no FAIMER-accredited medical school have population under 12 million and all but one have population under 4.5 million. Of the 36 countries with at least one FAIMER-accredited school, all but 7 have a population over 5 million.

For country size to serve as a valid instrument for health professional emigration, however, it must also be excludable from a regression with health staffing, primary care, or basic health outcomes as the dependent variable. In this case, that means that country size should not affect any of these variables except through its effect on emigration rates. There is a strong case for excludability. Recall that the emigration indicator used here is based on country of birth. Nothing about the argument above suggests that a person born in a smaller country is more or less likely to be a physician, all else equal, than someone born in a larger country. That person may choose not to work as a physician in a place with few goods and services that complement the profession (small countries), but this effect acts solely through migration. It may be, of course, that for other reasons than those discussed so far, being small makes a country less likely to raise children who choose to become or are able to become health professionals. Small countries could be poorer, for example, and poverty could stunt their mental development. Small countries could also experience greater emigration of teachers, limiting children's access to childhood learning that enables them to qualify for professional schools.

But there is little empirical support for this theoretical concern. Rose (2006) tests whether or not smaller countries differ from larger ones on a wide range of development indicators. He finds no systematic differences due to country size per se in income per capita, public health outcome and treatment indicators like child mortality or vaccination rates, and indicators of the strength of the education system such as the literacy or the primary school completion rate. ${ }^{2}$ This suggests that there is little reason to be wary of the excludability of country size in this case. This empirical evidence aside, there is much theoretical unease in the trade literature on the validity of geographical variables like country size in regressions like this, and Rodríguez and Rodrik (2001) provide evidence that some of Frankel and Romer's geographic instruments for trade in

\footnotetext{
${ }^{2}$ Rose actually uses $\ln$ (population) as his measure of size rather than land area, but in the 53 African countries, the correlation between $\ln$ (population) and $\ln$ (land area) is 0.79 (from the World Bank Africa Database 2004, data year 2000).
} 
regressions with income per capita as the dependent variable are not excludable (though note that country size is not among these). To be on the safe side, we thus include in the main equation income per capita and basic schooling rates in all regressions that use country size as an instrument.

\subsection{Other instruments}

A further consequence of Africa's international borders is that economic conditions in the natural receiving countries vary importantly across sending countries. Doctors have high salaries in the United States, for example, but this labor market is less accessible to African physicians who learned their trade in French. This provides another potentially useful quasi-experiment.

A large body of empirical evidence suggests that relatively favorable economic conditions in the principal destination countries are a powerful cause of emigration from Africa (e.g. Hatton and Williamson 2003). To the extent that health system staffing and public health conditions in African countries are otherwise unaffected by destination-country prosperity, indicators of the latter could constitute valid instruments for emigration. Here we use receiving-country income per capita and average profession-specific wages in the receiving country as two such instruments.

This is made slightly complex by the fact that for several African sending countries, multiple destination countries are important. Here we create for each sending country an index of destination-country income per capita as the weighted average of income per capita across the nine principal receiving countries. A second index is the weighted average of profession-specific wages in the nine principal receiving countries, gathered by an international salary consulting firm. When these indices instrument for physician (professional nurse) emigration, the weights in each case are the fraction of physicians (professional nurses) born in that sending country who live in each receiving country.

While it is difficult to imagine how an increase in (say) physician wages in Belgium could per se directly affect public health in Burundi through any other channel than migration, it is much more likely that income per capita in Belgium could affect economic and social development in Burundi through multiple channels. In such a case, the instrument would be nonexcludable from the main regression equation and thus invalid. For this reason we run each instrumented regression with and without these two additional instruments, and include always an indicator of income per capita in the main equation.

With these elements in place - an indicator of emigration, a set of outcomes of interest, and a set of natural experiments - the data are in place to test the null hypothesis of no effect of health professional 
emigration on staffing and health outcomes. Table 1 summarizes all the variables, both unlogged and logged (since all regressions are in logs).

\subsection{Results: The effect of health workers abroad on domestic stocks}

Table 2 investigates the causal effect of physicians abroad on the number of physicians in each African country, both measured per capita in the sending country. All regressions are based on equation (11). The unit of observation is the African sending country. The indicator of physician emigration in the first row is the number of physicians who live and work abroad, in the year 2000, born in each sending country, per capita in the sending country. Regression (1) is the simple bivariate correlation from Figure 4, revealing a strong positive correlation.

What produces the positive correlation? Some of the most obvious candidates that could simultaneously affect both variables in an African context are wealth, education systems, and warfare. Regression (2) controls for income per capita - strongly positively correlated with physicians per capita - as well as primary school enrollment and a dummy variable for a major war between 1970 and 1999. The correlation between physician emigration and domestic physician stocks weakens somewhat in magnitude by remains statistically significantly positive at less than the $1 \%$ level.

Additional omitted variables could still be driving this correlation, biasing upward the coefficient on emigration by generating correlation between that variable and the error term. We can address that violation of the regression model's assumptions with good instruments - correlated with emigration but with no direct effect on domestic physician stocks. Regression (3) shows that francophonie and country size are indeed correlated with emigration to a statistically significant degree. An F-test rejects the hypothesis that their coefficients are jointly zero at less than the $1 \%$ level. They jointly explain roughly one fifth of the variance in physicians abroad per capita. Including desination physician wages or destination income per capita in regression (4) does not improve identification.

Regression (5) re-runs regression (2), this time instrumenting for physicians abroad per capita using only francophonie and country size, the instruments that emerge from Proposition 3. Regression (6) uses all four instruments from regression.(4). The sign on physicians abroad remains positive but the coefficient is statistically indistinguishable from zero. To the extent that the instruments are valid, there is no discernible negative effect of physician emigration on domestic physician stocks. Regressions (7) and (8) show the first-stage results from regressions (5) and (6). 
Regressions (9) and (10) employ the more efficient three-stage least squares estimator to take advantage of information contained in the cross-equation correlations of error terms. The coefficient on the physician diaspora size rises slightly and the standard error falls slightly.

Finally, regression (11) uses the stock of physicians outside each African country, per capita in the sending country, calculated by Bhargava and Docquier (2006). While this measure combines country of training, country of birth, and country of citizenship to define an 'African' physician abroad - differing according to the receiving country where data were gathered - it focuses on country of training in key destination countries like the US, UK and France. It is thus an independent indicator of cumulative physician emigration using a substantially different definition of 'emigrant doctor'. The results do not change The correlation between this measure of emigrant physicians and that in row 1 of the table, based on country of birth, is 0.73 .

Table 3 repeats precisely the same analysis described above, with the sole difference that professional nurses rather than physicians are considered in every instance. The conclusions are the same in all but insubstantial details.

\subsection{Results: The effect on basic health care and public health outcomes}

Table 4 makes only one adjustment to the preceding analysis. The dependent variable in the upper half of the table - regressions (1), (2), (5), (6), and (9) to (11) - is mortality in children under age five per 1,000 live births. All regressions are based on equation (14). The table is an analytical extension of the simple correlation in Figure 5.

If physicians abroad at the massive levels seen in Figure 2 substantially degrades basic public health conditions, we might expect a positive coefficient on the migration variable. The coefficient on physicians abroad never positive and is often statistically distinguishable from zero. This remains true when two-stage least squares and then three-stage least squares attempt to isolate the causal impact of physicians abroad on child mortality, with increasing efficiency. With the expanded instrument set that includes destination physician wage and destination income per capita in regression (6), the instruments come close to failing Hansen's excludability test at the $5 \%$ level. Restricting the instrument set to the more parsimonious pair of Francophone and land area, however, eliminates this correlation in regression (5). And these two instruments are preferred at any rate, since the first-stage regressions (7) and (8) and the Anderson canonical correlation test in regressions (5) and (6) make it clear that those two contain all the first-stage explanatory power. The Anderson-Rubin test in regression (8) comes close to rejecting the hypothesis that the coefficient on physician emigration is zero, but note that the sign of the coefficient is negative. 
Table 5 repeats the above analysis for professional nurses. Again, there is no evidence that even the huge numbers of nurses abroad seen in Figure 3 have any positive causal effect on child mortality. The qualitative conclusions from the preceding paragraph apply equally to this table, with two exceptions. One exception is that Hansen's test comes nowhere near rejecting the null of nonexcludable instruments in this case. The other is that the hypothesis of a zero coefficient on nurses abroad in all regressions is rejected at the $5 \%$ level with the simple $t$ or $z$ statistic, and rejected in regressions (5) and (6) at the $10 \%$ level with the Anderson-Rubin statistic. That is, these regressions are suggestive of a small negative causal effect of nurse emigration - or something it proxies for — on child mortality.

Child mortality is certainly not the only indicator of public health. Tables 6 and 7 repeat the threestage least squares results of Table 4, regression (9), for ten other indicators of basic primary health care and public health outcomes that are widely available across African countries. These are: mortality under age one per 1,000 live births (IMR); the measles vaccination rate; the diptheria/pertussis/tetanus (DPT) vaccination rate; the prevalence of acute respiratory infections (ARI) in children under age five during two weeks requiring medical care; the fraction of those ARIs that saw a trained health professional; the percentage of deliveries attended by trained personnel; the percentage of children under age five with diarrhea requiring medical attention over a two-week period, the percentage of those diarrhea cases who received either oral rehydration therapy or increased fluids, with continued feeding; the percentage of people ages 15-49 who are infected with HIV; and the percentage of adults with advanced HIV infection receiving antiretroviral treatment.

The tests fail to detect any deleterious effect of physicians abroad on basic health care availability or mass public health outcomes in any of the ten cases. The coefficients on all the treatment variables (vaccinations, attended births, ARI treatment, diarrhea treatment, and HIV treatment) are uniformly positive. Thus even more efficient inference could not by itself reveal a negative effect of physician emigration on basic primary health care provision in these data. The coefficients on public health outcomes are negative (for infant mortality ARI prevalence, and diarrhea prevalence) with the exception of HIV prevalence-which is statistically indistinguishable from zero.

Two additional tables that repeat the analysis of Tables 6 and 7 for professional nurses are omitted here for brevity. There are two qualitative differences between those tables and the discussion above. The first is in the signs of a few coefficients: The coefficient on nurse migration is positive in the diarrhea prevalence regression, though statistically indistinguishable from zero with a z-statistic of 0.09. The second difference is that the negative coefficient on nurse migration in the regressions for infant mortality and ARI prevalence 
are negative and statistically significant, and the coefficient in regression for HIV treatment is positive and statistically significant.

In sum, we observe no causal connection whatsoever between the very large cross-country variance in African health worker diasporas and any of degradation of basic primary health care provision or public health outcomes in the sending-countries.

\subsection{Econometric issues}

We might have several concerns in interpreting these results, at least including weak instruments, nonexcludable instruments, inefficient inference, influential observations, and different classes of measurement error.

\subsubsection{Weak instruments}

First, regressions (3) and (4) in Tables 2 through 5 show that the instruments do explain a substantial portion of the variance in emigration and do so to a highly statistically significant degree in terms of the F-test. Likewise, the canonical correlation likelihood ratio test of Anderson (1951) rejects the null of weak instruments at the less than $1 \%$ level in all cases. Hall et al. (1996) and Stock et al. (2002), among others, argue that this is insufficient to rule out weak instrumentation especially in finite samples with invalid, endogenous instruments. Stock et al. recommend as one solution the test of Anderson and Rubin (1949) of the null hypothesis that the coefficient on the endogenous variable in the main equation is zero, a test that is fully robust to weak instruments. Here the null is not rejected at the $5 \%$ level anywhere except regression (6) in Table 3, where the coefficient on nurses abroad is positive.

Stock and Yogo (2005) calculate critical values below which the value of the Cragg-Donald (1993) statistic would suggest bias in the coefficient estimates. In the coefficient estimate in regression (5) of Table 2, Stock and Yogo's critical values suggest that with $95 \%$ confidence, the bias in the coefficient estimates on physicians abroad is less than $20 \%$ of the OLS bias. ${ }^{3}$ Instrumentation in regression (5) of Tables 3, 4, and 5 is likewise 'strong' by the definition of Stock and Yogo.

\subsubsection{Overidentification}

We might also be concerned that the instruments are endogenous and inappropriately excluded from the main equation. Controlling for income per capita, schooling, and warfare in the main equation-superfluous

\footnotetext{
${ }^{3}$ Taking the coefficients from columns (2) and (5), and letting $x$ represent the lower bound on the true coefficient, we have $0.20(0.36-x)+x=0.03$, thus $x=-0.05$. That is, we can be $95 \%$ confident that a one-percent increase in the size of the physician diaspora causes less than a one twentieth of one percent decrease in the stock of physicians in the sending country, or an increase in that stock.
} 
if the instruments are valid - allays this concern since the channels of direct causation from the instruments to physician stocks would have to bypass those variables to invalidate the instruments.

Furthermore, we discussed above several reasons to expect a priori that the instruments are in fact excludable. And the Hansen (1982) J-test fails to reject the null of zero correlation between the instruments and the estimated disturbances at the $5 \%$ level in Tables 2 to 5 . Since this test is based on estimated rather than true residuals, and thus relies on the assumption that at least one of the instruments is in fact valid, it is indicative rather than dispositive. But it does suggest that if there is any direct effect of the instrumental variables on physician stocks, it is very small. If tremendous cross-country differences in $c_{i}$ from equation (11) were driving these results - that is, if countries where health conditions were the worst were systematically those countries where the largest fraction of the health worker diaspora became health professionals after leaving - then we would expect to see a substantial correlation between the instruments and the error term, which includes $c_{i}$.

\subsubsection{Efficiency}

Next, we might be concerned that the limited information estimators in regressions (1) through (6) of Tables 2 to 5 fail to reject the hypothesis that the coefficient on physicians abroad is zero because they fail to take advantage of the additional information contained in the correlation between the error terms in the system of two equations. Certainly we should expect that some of the same unobserved country characteristics that create more doctors could also create more doctors who emigrate, information which a system estimator could exploit. Note however that the coefficient on health workers abroad is positive when the dependent variable is domestic health worker stocks, and negative when the dependent variable is child mortality. So inefficient inference could not be a reason why the estimation does not detect any negative impact of emigration on domestic health worker stocks or any positive impact on child mortality. As we move to a full-information three-stage least squares estimator in regressions (9) and (10) of each table, we see no change in these patterns.

\subsubsection{Influential observations}

In this small-sample setting we might be concerned that a single influential observation is unduly affecting the coefficient estimate on physicians abroad. Figures 4 and 5 certainly suggest that this is not the case for physicians abroad or for domestic physician stocks per se. Among the covariates, an obvious candidate for extreme distortion is the GDP per capita of Equatorial Guinea, which shot to the stratosphere after oil wells came online during the 1990s and which grew $67 \%$ in 1997 alone. The results are not qualitatively sensitive 
to the omission of any one country, including Equatorial Guinea. To the extent that the instruments are valid, of course, the covariates should not affect the coefficient estimate on physicians abroad at all.

\subsubsection{Nonclassical measurement error in health workers abroad}

Not all health professionals living outside their country of birth would have become health professionals if they had not left that country. To the extent that this fraction does not vary across countries it does not bias the above estimates at all. To the extent that it varies across countries but is uncorrelated to the size of the diaspora there is no bias either. But if it is correlated with the diaspora size, bias could be present. In other words, if $c_{i}$ is strongly correlated with $l_{i}^{*}$, then the coefficient estimates on $l_{i}^{*}$ in regression equations (11) and (14) will be biased.

Empirically, the best way to address this concern would be to measure $l_{i}^{\prime}$ directly. As discussed above, a country-of-training based emigration measure is a very imperfect measure of $l_{i}^{\prime}$, but is biased in different ways than a measure based on country of birth. In Tables 2 and 4, using a measure that focuses primarily on country of training does not change the result. Since all those trained in the country of origin were health professionals at departure, this is a strong reason to believe that the other regression results are not spuriously generated by correlation between $l_{i}^{*}$ and $c_{i}$.

Another approach would be to find an experiment provoking variance in $l_{i}^{*}$ but not in $c_{i}$, that is, exogenous variation in health worker emigration that does not change the incentives of people to become health professionals if they could not leave the country. The natural quasi-experiments above may not meet this criterion. The approach we take here is to find a variable likely to be correlated with the propensity to become a health professional in the counterfactual case of staying at home - age at emigration - and consider whether or not it is correlated with total emigration $l_{i}^{*}$.

Certainly the age at migration must be strongly correlated with the propensity to become a health professional in the counterfactual case of having remained in the country of origin. A person born in Nigeria who works in the UK as a physician, and emigrated at age 45 , is extremely likely to have been a physician in Nigeria since extremely few foreign students who finish a British medical degree do so after age 50. Conversely, only a limited fraction of Nigerian-born physicians in the UK who emigrated at age 5 would have been physicians if they had not left Nigeria. If those African countries with the largest health worker diasporas also contain the largest fractions of those who departed at a young age, before becoming health professionals, this would suggest that $\operatorname{corr}\left(l_{i}^{*}, c_{i}\right)<0$ and that the estimates of the preceding tables reflect a lower bound on the true effect. 
But we do not observe such a correlation in survey data on African-born physicians in the United States, Canada, and France. Table 8 reports these results. The first row uses the Public Use Microdata Sample (5\%) of the United States census from the year 2000, which reports interviews with 614 physicians born in one of 18 African countries. Each individual reports an age in 2000 as well as the year of arrival in the US, allowing unbiased estimation of that person's age at arrival. This age is then averaged within each of the 18 countries of birth. OLS regressions in columns 1 and 3 show that this average is not correlated across sending countries to a statistically significant degree with physicians per capita abroad or the fraction of physicians abroad, the regressors from Tables 2, 4, 6, and 7. The reliability of these averages varies, of course: The sample represents a population of 21 doctors born in Senegal but 2,767 born in Nigeria. For this reason columns 2 and 4 repeat the regressions with analytical weights inversely proportional to census population estimates for each country of birth. There is no meaningful correlation between the age at emigration and physicians per capita abroad. There is weak evidence of a small negative correlation between age at emigration and the fraction of physicians abroad. But it is not statistically significant at the $5 \%$ level, and more importantly, it suggests that a near tripling of the fraction of physicians abroad is correlated with a decline in the emigration age of just 0.2 years. This suggests a miniscule bias to the earlier coefficient estimates.

Rows 2 and 3 of the table use a survey of 1,752 physicians born in 31 African countries living in the US and Canada in 2006, detailed in Clemens (2006). Row 2 uses survey questions regarding year of birth and year of arrival in the US or Canada to create an unbiased estimate of the individual's age at arrival and repeats the analysis of row 1, finding no evidence of a negative correlation between migration age and diaspora size. Row 3 creates a dummy variable for each individual taking the value 1 if he or she arrived in the US or Canada earlier than six years before earning his or her medical degree (about $18 \%$ of the sample). Such a person probably did not go abroad for the express purpose of becoming a physician and may not have decided upon a career at the moment of emigration. Here we would expect a strong positive coefficient if $\operatorname{corr}\left(l_{i}^{*}, c_{i}\right)<0$, but there is no evidence of such a correlation.

Finally, row 4 uses the microdata 25\% sample of the 1999 census of France, which reports survey forms filled out by 2,664 individual physicians born in 37 African countries. The year of arrival in France is not recorded. But for countries of birth whose physicians typically emigrated to France later in life, after their medical degrees (and thus highly likely to be physicians if they had not emigrated), the typical reported age should be higher than that for countries of birth whose physicians typically emigrated prior to their degree and thus enter the sample immediately upon graduation. We do see weak evidence of an extremely small negative correlation between age in 1999 and the emigration indicators. But the coefficients are not statistically significant, and they are tiny; a near tripling of emigration rates correlates with a decline in 
average age of about 0.1 years.

\section{Aside: The causes of health professional emigration}

We note in passing that Tables 2 and 3 suggest the magnitudes of a few important determinants of health professional emigration from Africa. Two of these are income per capita and the occurrence of a major war.

Doctors and nurses tend to leave richer African countries than poorer ones. The elasticity of physicians per capita abroad with respect to sending-country income per capita is about 0.7 (Table 2), for nurses about 0.5 (Table 3). Both are positive and statistically significant at the $1 \%$ level. This is in line with the evidence presented by Hatton and Williamson (2005) that in the poorest countries - and there aloneeconomic development appears to encourage emigration by helping potential emigrants overcome fixed costs associated with working overseas.

Lucas (2005, Ch. 3) argues that this evidence of an empirical "inverted-U" relationship between income per capita and emigration is not robust across all countries and for the mass of migrants. But this is not incompatible with the notion that of an inverted-U relationship for high-skill professions in the poorest countries. In addition to overcoming fixed costs, potential high-skill migrants must acquire sufficient human capital to compete in the global labor market. Economic development and its associated higher quality training may assist in such competitiveness. Certainly the fact that South African nurses are in higher demand internationally than their Sierra Leonean colleagues has to do with more than the ability of the former to pay for airline travel; South African nursing schools have a superior ability to meet international training standards. A case in point of this phenonmenon may be Rwanda, where strong economic recovery and stability following the genocide have allowed the Kigali Health Institute to recently become the first and only producer of fully-fledged Registered Nurses in a country that traditionally has only trained preprofessional ("A2") nurses. Given that Registered Nurses are in far higher demand abroad than vocational nurses, it is quite possible that the emigration of Rwandan nurses could correspondingly increase.

The data make it clear that major wars are associated with a tremendous exodus of skilled health professionals, a phenomenon that has not heretofore been systematically measured. "Major" war constitutes more than 25 battle-related deaths per year and a total conflict history of more than 1000 battle-related deaths. The sample average of the log of physicians per capita abroad is -0.569 , which increases on average by about 0.6 in countries that have experienced major warfare in the preceding thirty years (Table 2 , regression (9)). The change is statistically significant at the $2 \%$ level. In other words, expected physician migration 
nearly doubles, from about 0.6 physicians per 10,000 population to about 1.0, in countries touched by war. The effect is persistent across decades. For nurses, warfare is associated with a jump of nurses abroad per 10,000 population from 0.7 to 1.6, again roughly a doubled exodus. This difference is statistically significant at the $1 \%$ level. To the other consequences of African wars we may add another: doubling the departure of a country's health care providers.

\section{Conclusion}

\subsection{Empirical observations}

Tables 2 and 3 suggest some lessons. First, we have a partial suggested answer to the question of whether the positive correlation between health professional emigration and health professional stocks is driven by positive causation from emigration to stocks, positive causation from stocks to emigration, or by third factors. The first effect - a positive effect of migration on domestic stocks, for example as foreign opportunities encourage young people to enter the health field - is not large enough to be the driving force. Instead, the big determinant of the positive correlation is some combination of the effects of large domestic stocks in countries ill-equipped to absorb new physicians domestically (causation from stocks to emigration) and national characteristics that raise production and emigration simultaneously (such as the quality of medical schools).

Second, the negative effect of emigration on domestic stocks, an accounting identity, is being counteracted by some positive effect of emigration on domestic stocks such that the net effect is too small to be observed. Since almost half the countries in question have lost more than $40 \%$ of their physicians, the effect should be easy to observe in the absence of a large countervailing force. To the extent that the instruments used here are valid, and because the negative effect of emigration on stocks is an identity, the existence of a simultaneous strong positive effect of migration on stocks is the only reason the effect of migration on stocks could be zero in Table 2. Analysis of this type does not illuminate the nature of this countervailing force. It could be supply-driven, as African governments are typically able to increase the production of physicians and nurses to replace those who have left. It could be demand-driven, as people enter the medical field in greater numbers encouraged by the foreign success of their departed compatriots. Whatever it is, it has been

sufficient to totally counteract any staffing effect from even the massive exoduses of health personnel seen in Figures 2 and 3.

Third, we might have reasons to believe that emigration could degrade health outcomes or erode the availability of care, even if the emigrants are replaced by new entrants to the profession. Emigration could 
affect the domestic distribution of health professionals, for example by pulling them into urban areas and into the private sector to replace emigrants from those sectors. Emigration could also change the average level of training or experience in the domestic workforce, as younger professionals with less training replace those who are recruited abroad. This could have short term consequences for the quality of care and longterm consequences on professional pedagogy. But if these things are happening systematically across Africa, we see no evidence that they substantially affect the eleven indicators of mass primary care availibility and public health outcomes tested here.

The empirical literature on the sending-country effects of migration is in its infancy. We certainly need better measures of migration - in particular, thoughtful agreement on the definition of a 'migrant' - and we need better natural (and even designed) experiments. This takes a stance on both issues, employing adequate though problematic indicators of emigration and imperfect but provocative natural experiments. Much can be learned, this paper claims, even with this flawed machinery. The field nevertheless remains wide open to improved measures of worker movement and to creative experiments with greater internal and external validity.

\subsection{The missing link between migration and sending-country welfare: Health systems}

Many health economists find this quite intuitive, even if migration researchers do not. But if we seek to set migration policy to maximize welfare, we must understand the health systems that translate human resources into social welfare. The state of those systems is dire, but it is not at all clear that a dearth of persons is a greater constraint than the incentives those persons face.

The domestic distribution of health professionals across the continent is already highly skewed away from sectors relevant to the poor masses (Serneels et al. 2005). That is, only a small minority of the most highly trained health professionals (the ones most competitive abroad) in essentially all African countries spend a substantial portion of their time working in rural areas and slums. The number of trained health professionals within South Africa and Kenya who work outside the public sector or entirely outside the health sector greatly exceeds the number who work outside the country (e.g. Hall and Erasmus 2004, p. 537; Personal communication from the the National Nurses Association of Kenya, April 25. 2006). A study of ten Tanzanian government health centers found that $26 \%$ of staff time was wasted on "breaks, waiting for patients, ... social contacts and ... unexplained absences" (Kurowski et al. 2004). In Uganda, unannounced visits to 100 government-run health facilities found $37 \%$ of care providers were simply not there at a time 
they were being paid to be working (Chaudhury et al. 2006). And that is in the clinics where people had accepted jobs; many rural clinics across Africa can find no one at all to fill them. But it is specious to suggest, as many do, that such unfilled positions are primarily a function of the number of health workers who are somewhere within the national borders. By and large, incentives are insufficient to convince existing workers to take those jobs, and it is unclear why this would be less true for a potential emigrant whose pathway is blocked by visa caps or recruitment bans.

Moreover, the extensive skills of highly-trained primary care providers have may be very ill-suited to address the principal causes of mass morbidity and mortality among the poor (e.g. Filmer, Hammer, and Pritchett 2000, 2002; Canning 2006). Children do not die in rural Mozambique primarily due to a lack of cardiologists and nurse practitioners; they die principally from lack of oral rehydration during diarrhea, lack of malaria prophylaxis, and lack of basic primary treatment for acute respiratory infections. None of these require highly trained personnel to deliver. This is true even at the heart of the HIV catastrophe; in Zambia only $16 \%$ of child death is HIV related (WHO-AFRO 2006, p. 135). These effects accord with the model here; equation (9) suggests that the public welfare effect of a health professional is smallest in countries where domestic market failures are most pronounced, and that the impact of a highly-trained health professional is smallest in countries where that person can be substituted by a less-trained professional capable of delivering the same care or-better in many cases - working for prevention.

As Karl Popper and others have argued, it is impossible to prove a null hypothesis. The zero coefficient spanning the first row of many of these regression tables does not "prove" anything. But why is it that no staffing or public health effects due to emigration per se are observable even across countries that have lost half or even two thirds of their health professionals to emigration? Perhaps it is that the world is complex, and superimposing an additional market failure - an impermeable border — onto the myriad other failures in developing countries does little to improve welfare in a second-, third-, or tenth-best economy. Punishing emigration, restricting quotas, and banning recruitment, while as plausible as import-substituting industrialization once was, and for similar reasons, may at best make no one better off and at worst make everyone worse off. 


\section{References}

Aitken, Norman D. (1968), "The international flow of human capital: Comment", American Economic Review 58 (3): 539-545.

Alesina, Alberto, Enrico Spolaore, and Romain Wacziarg (2005), "Trade, growth, and the size of countries", Chap. 23 in Philippe Aghion and Steven N. Durlauf, eds., Handbook of Economic Growth, I. B. (New York: Elsevier), pp 1499-1542.

American Medical Association (2007), "Practicing Medicine in the US" [http://www.amaassn.org/ama/pub/category/10141.html], accessed January 26.

Anderson, T.W. (1951), "Estimating linear restrictions on regression coefficients for multivariate normal distributions", Annals of Mathematical Statistics, 22 (3): 327-351.

Anderson, T. W. and Herman Rubin (1949), "Estimation of the parameters of a single equation in a complete system of stochastic equations", Annals of Mathematical Statistics 20 (1): 46-63.

Awases, M., A. Gbary, J. Nyoni, and R. Chatora (2004), Migration of Health Professionals in Six Countries: A Synthesis Report (Brazzaville, Rep. of Congo: World Health Organization Regional Office for Africa).

Barro, Robert J. and Jong-Wha Lee (2000), "International Data on Educational Attainment: Updates and Implications", CID Working Paper No. 42, Kennedy School of Government (Cambridge, MA: Harvard University).

Beine, Michel, Frédéric Docquier, and Hillel Rapoport (2001), "Brain drain and economic growth: Theory and evidence", Journal of Development Economics 64 (1): 275-289.

Beine, Michel, Frédéric Docquier, and Hillel Rapoport (2003), "Brain drain and LDCs' growth: Winners and losers", IZA Discussion Paper 819 (Bonn: Forschungsinstitut zur Zukunft der Arbeit).

Bhargava, Alok and Frédéric Docquier (2006), "HIV pandemic, medical brain drain and economic development in sub-Saharan Africa", Working Paper, Dept. of Economics (Houston, Texas: University of Houston)

Canning, David (2006), "The Economics of HIV/AIDS in Low-Income Countries: The Case for Preventio", Journal of Economic Perspectives 20(3): 121-142.

Chaudhury, Nazmul, Jeffrey Hammer, Michael Kremer, Karthik Muralidharan, and F. Halsey Rogers (2006), "Missing in Action: Teacher and healther worker absence in developing countries", Journal of Economic Perspectives 20(1): 91-116.

Clemens, Michael A. (2006), "The financial impact of African health worker emigration," forthcoming Working Paper (Washington, DC: Center for Global Development).

Clemens, Michael A. and Gunilla Pettersson (2006), "A new database of health professional emigration from Africa", Working Paper 95 (Washington, DC: Center for Global Development).

Cragg, John G. and Stephen G. Donald (1993), "Testing identifiability and specification in instrumental variables models", Econometric Theory 9(2): 222-240.

Curtin, Philip, Steven Feierman, Leonard Thompson, and Jan Vansina (1978), African History (Boston: Little, Brown and Co.).

Docquier, Frédéric and Hillel Rapoport (2004), "Skilled migration: The perspective of developing countries", World Bank Policy Research Working Paper 3382 (Washington, DC: World Bank).

Docquier, Frédéric and Abdeslam Marfouk (2005), "International Migration by Educational Attainment (1990-2000) - Release 1.1", update of World Bank Policy Research Working Paper 3381 (Washington, DC: World Bank). 
Dumont, Jean-Christophe, and Georges Lemaître (2005), "Counting immigrants and expatriates in OECD countries: A new perspective," Directorate for Employment Labour and Social Affairs (Paris: OECD).

Educational Commission for Foreign Medical Graduates (2007), International Medical Education Directory (IMED) [http://imed.ecfmg.org], accessed January 26.

Fage, J. D. (1978), A History of Africa (New York: Alfred A. Knopf).

Filmer, Deon, Jeffrey S. Hammer, and Lant H. Pritchett (2000), "Weak Links in the Chain: A diagnosis of health policy in poor countries", World Bank Research Observer 15(2): 199-224.

Filmer, Deon, Jeffrey S. Hammer, and Lant H. Pritchett (2002), "Weak Links in the Chain II: A prescription for health policy in poor countries", World Bank Research Observer 17(1): 47-66.

Frankel, Jeffrey A. and David Romer (1999), "Does trade cause growth?" American Economic Review 89 (3): 379-399.

Gallup, John Luke, Jeffrey D. Sachs, and Andrew Mellinger (1998), "Geography and Economic Development" in Boris Pleskovic and Joseph E. Stiglitz, eds., Annual World Bank Conference on Development Economics 1998 (The World Bank: Washington, DC).

Gann, L. H. (1969), "Reflections on imperialism and the scramble for Africa", in L. H. Gann and Peter Duignan, eds., Colonialism in Africa, 1870-1960 (New York: Cambridge University Press).

Grubel, Herbert G. and Anthony D. Scott (1966), "The international flow of human capital", American Economic Review 56 (1/2): 268-274.

Grubel, Herbert G. and Anthony D. Scott (1968), "The international flow of human capital: Reply", American Economic Review 58 (3): 545-548.

Hagopian, Amy, Matthew J. Thompson, Meredith Fordyce, Karin E. Johnson and L. Gary Hart, (2004), "The migration of physicians from sub-Saharan Africa to the United States of America: Measures of the African brain drain", Human Resources for Health 2: 17.

Hall, Elsje and Johan Erasmus (2004), "Medical practitioners and nurses", in HSRC, Human Resources Development Review 2003 (Pretoria: Human Sciences Research Centre), pp.523-53.

Hamilton, Bob and John Whalley (1984), "Efficiency and distributional implications of global restrictions on labor mobility", Journal of Development Economics 14 (1): 61-75.

Hansen, Lars Peter. (1982), "Large Sample Properties of Generalized Method of Moments Estimators", Econometrica 50 (4): 1029-1054.

Harris, John R. and Michael P. Todaro (1970), "Migration, unemployment, and development: A two-sector analysis", American Economic Review 60 (1): 126-142.

Hatton, Timothy J. and Jeffrey G. Williamson (2003), "Demographic and Economic Pressure on Emigration out of Africa", Scandiavian Journal of Economics 105 (3): 465-486.

Hatton, Timothy J. and Jeffrey G. Williamson (2005), "What fundamentals drive world migration?", in George J. Borjas and Jeff Crisp, eds., Poverty, International Migration and Asylum (New York: Palgrave Macmillan), pp. 15-38.

Kurowski, Christoph, Kaspar Wyss, Salim Abdulla, N'Diekhor Yémadji and Anne Mills (2004), "Human Resources for Health: Requirements and Availability in the Context of Scaling-Up Priority Interventions in Low-Income Countries", HEFP working paper 01/04 (London: London School of Hygiene and Tropical Medicine).

La Porta, Rafael, Florencio López de Silanés, Andrei Shleifer, and Robert W. Vishny (1997), "Legal determinants of external finance", Journal of Finance 52 (3): 1131-1150. 
Lucas, Robert E. B. (2005), International Migration Regimes and Economic Development (Northampton, MA: Edward Elgar Publishing).

McEwan, P. J. M. (1968), Nineteenth-Century Africa (London: Oxford University Press).

Miyagiwa, Kaz (1991), "Scale economies in education and the brain drain problem", International Economic Review, 32 (3), 743-759.

Moses, Jonathon W. and Bjørn Letnes (2004), "The economic costs to international labor restrictions: Revisiting the empirical discussion", World Development 32 (10): 1609-1626.

Mountford, Andrew (1997), "Can a brain drain be good for growth in the source economy?" Journal of Development Economics 53 (2): 287-303.

Mullan, Fitzhugh (2005), "The metrics of the physician brain drain", New England Journal of Medicine $353: 1810-1818$.

Oliver, Roland and Anthony Atmore (2005), Africa Since 1800, 5th ed. (New York: Cambridge University Press).

Oliver, Roland and J. D. Fage (1963), A Short History of Africa (New York: NYU Press).

Oosthuizen, Martha Johanna (2005), An analysis of the factors contributing to the emigration of South Africa nurses, PhD dissertation, Department of Health Studies (Pretoria: University of South Africa).

Rodríguez, Francisco and Dani Rodrik (2001), "Trade policy and growth: A skeptic's guide to the crossnational evidence", in Benjamin Bernanke and Kenneth S. Rogoff, eds. Macroeconomics Annual 2000 (Cambridge, MA: MIT Press).

Sanderson, G. N. (1985), "The European partition of Africa: Origins and Dynamics", in Roland Oliver and G. N. Sanderson, eds., The Cambridge History of Africa, Vol. 6 (New York: Cambridge University Press).

Serneels, Pieter, Magnus Lindelöw, José García Montalvo, Abigail Barr (2005), "For public service or money: Understanding geographical imbalances in the health workforce", Policy Research Working Paper 3686 (Washington, DC: World Bank).

Stark, Oded, Christian Helmenstein, and Alexia Prskawetz (1997), "A brain gain with a brain drain", Economics Letters 55 (2): 227-234.

Stark, Oded, Christian Helmenstein, and Alexia Prskawetz (1998), "Human capital depletion, human capital formation, and migration: a blessing or a 'curse'?" Economics Letters 60 (3): 363-367.

Stark, Oded and Yong Wang (2002), "Inducing human capital formation: migration as a substitute for subsidies", Journal of Public Economics 86 (1): 29-46.

Stock, James H., Jonathan H. Wright, and Motohiro Yogo (2002), "A survey of weak instruments and weak identification in generalized method of moments", Journal of Business and Economic Statistics 20 (4): 518-529.

Stock, James H. and Motohiro Yogo (2005), "Testing for weak instruments in linear IV regression", in J. H. Stock and D. W. K. Andrews (eds.), Identification and Inference for Econometric Models: Essays in Honor of Thomas J. Rothenberg (New York: Cambridge University Press).

Touval, Saadia (1966), "Treaties, borders, and the partition of Africa", Journal of African History 7(2): 279-293.

Walmsley, Terrie L. and L. Alan Winters (2005), "Relaxing the Restrictions on the Temporary Movement of Natural Persons: A Simulation Analysis", Journal of Economic Integration,.20 (4): 688-726.

WHO (2006), World Health Report 2006 (Geneva: World Health Organization).

WHO-AFRO (2006), African Regional Health Report 2006 (Brazzaville: World Health Organization African Regional Office). 


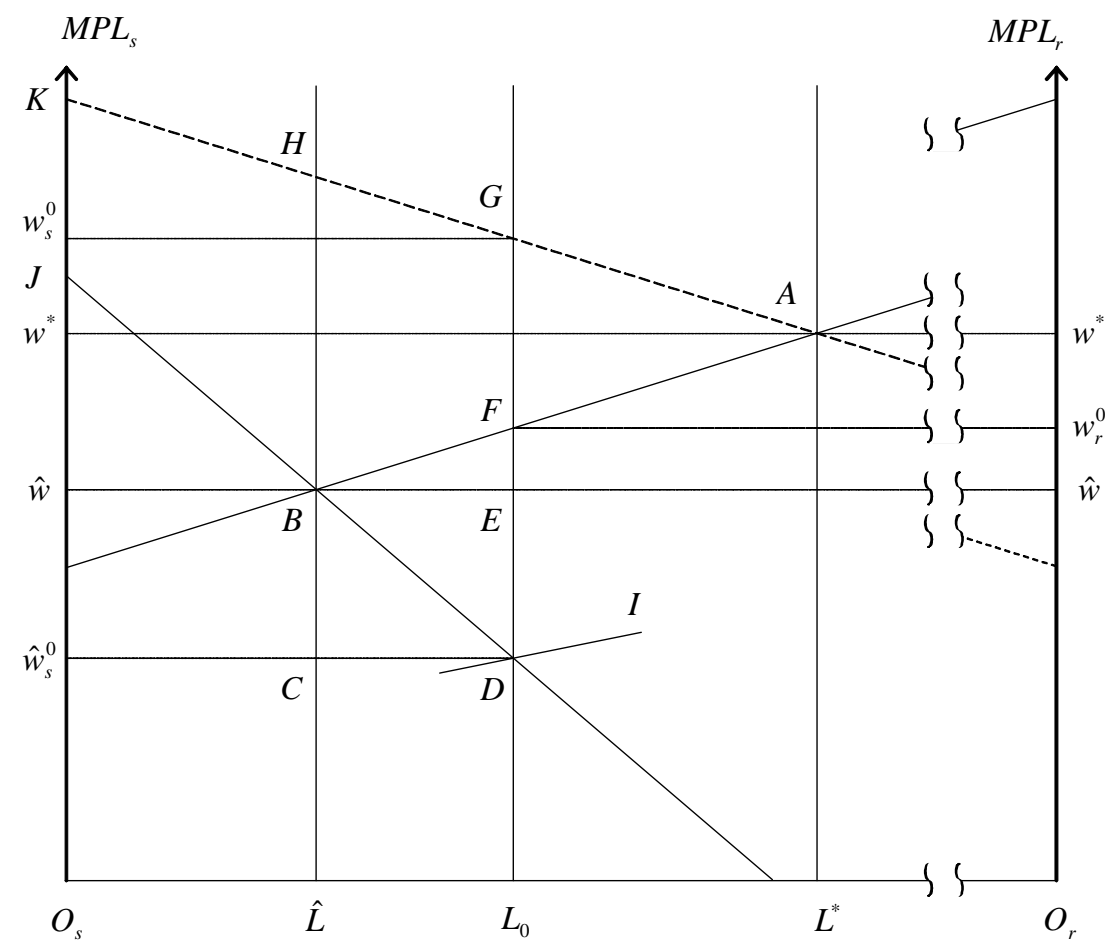

Figure 1: A simple welfare analysis of skilled migration 
Figure 2: Fraction of physicians abroad, 2000

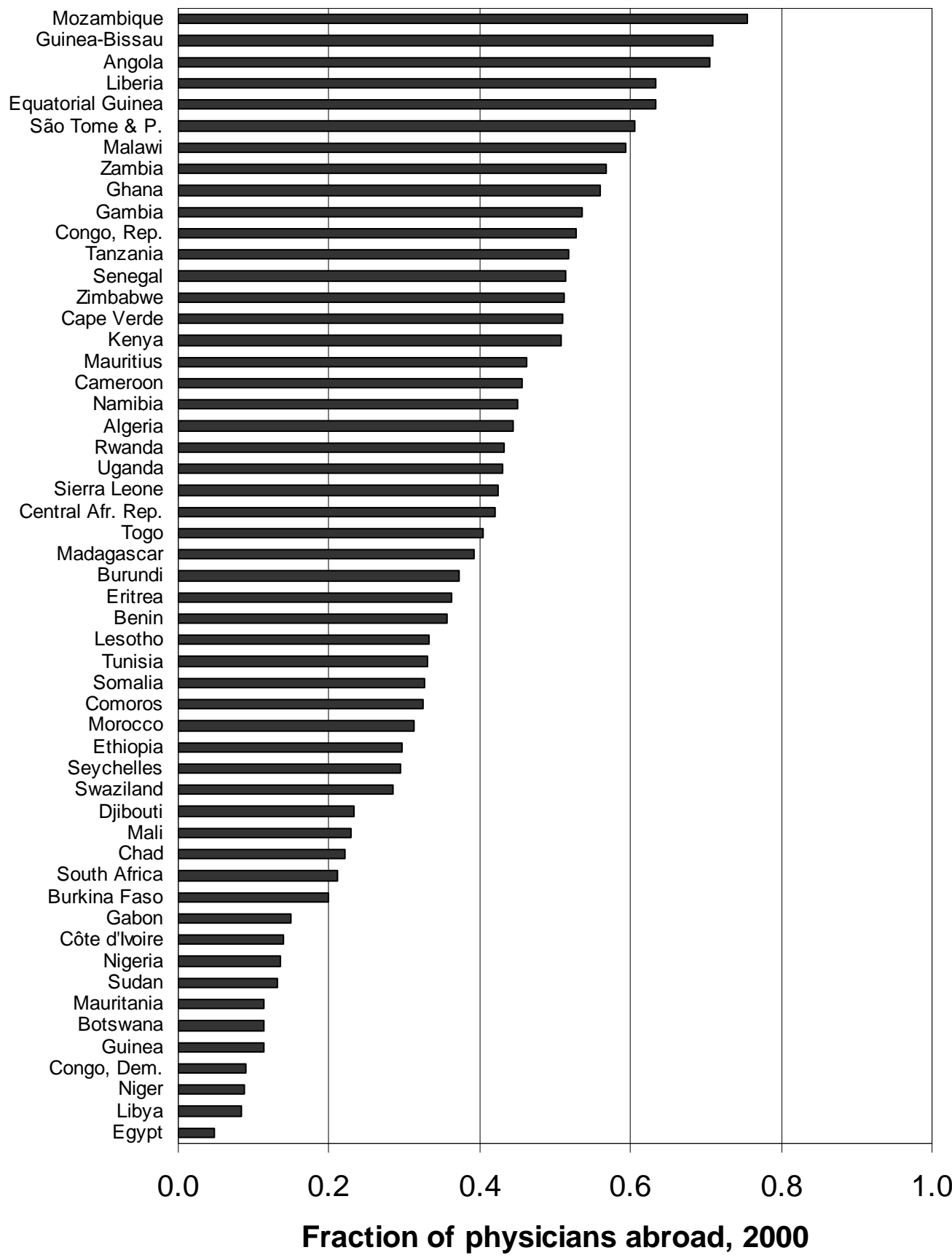


Figure 3: Fraction of professional nurses abroad, 2000

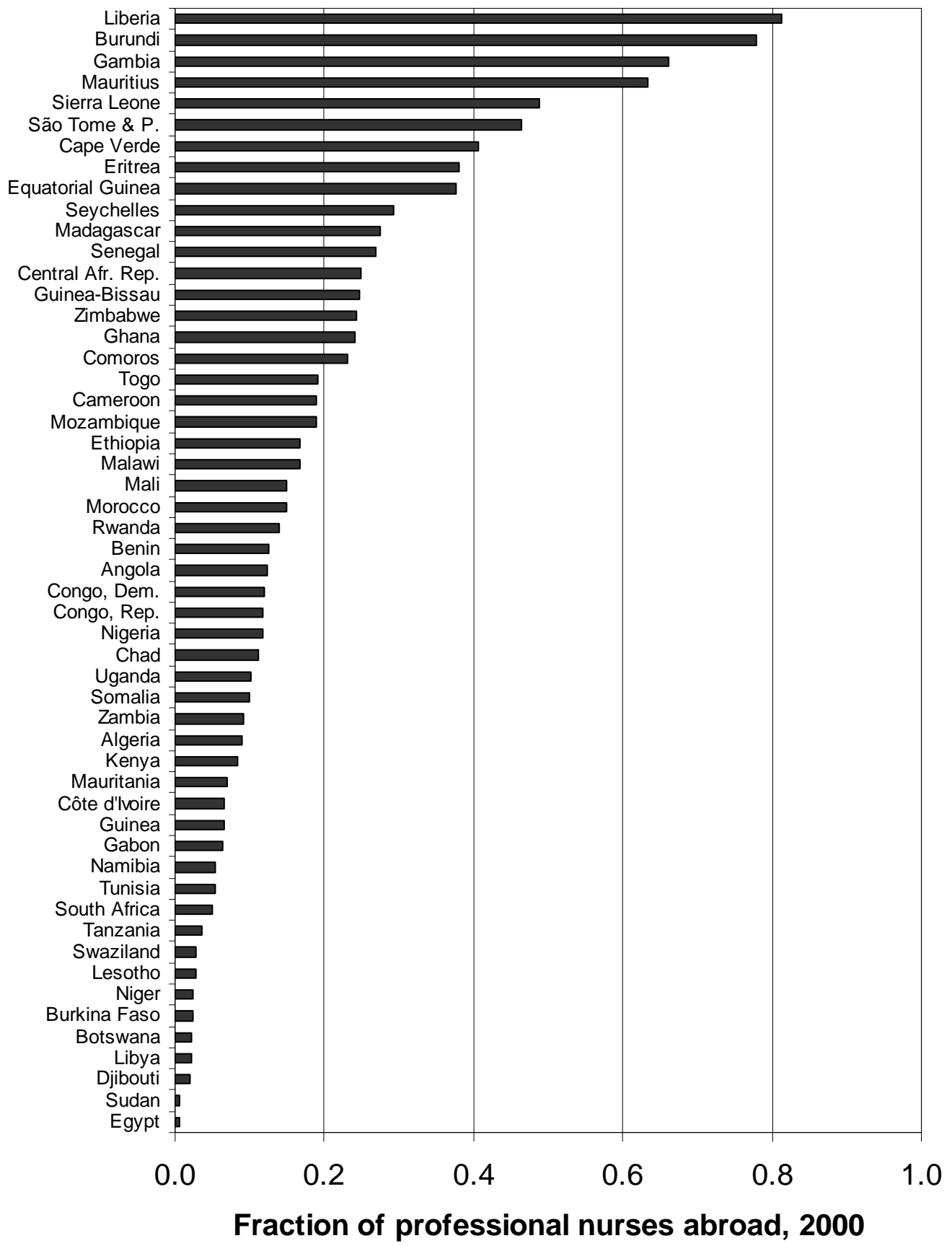


Figure 4: Simple correlation between physicians per capita at home vs. abroad

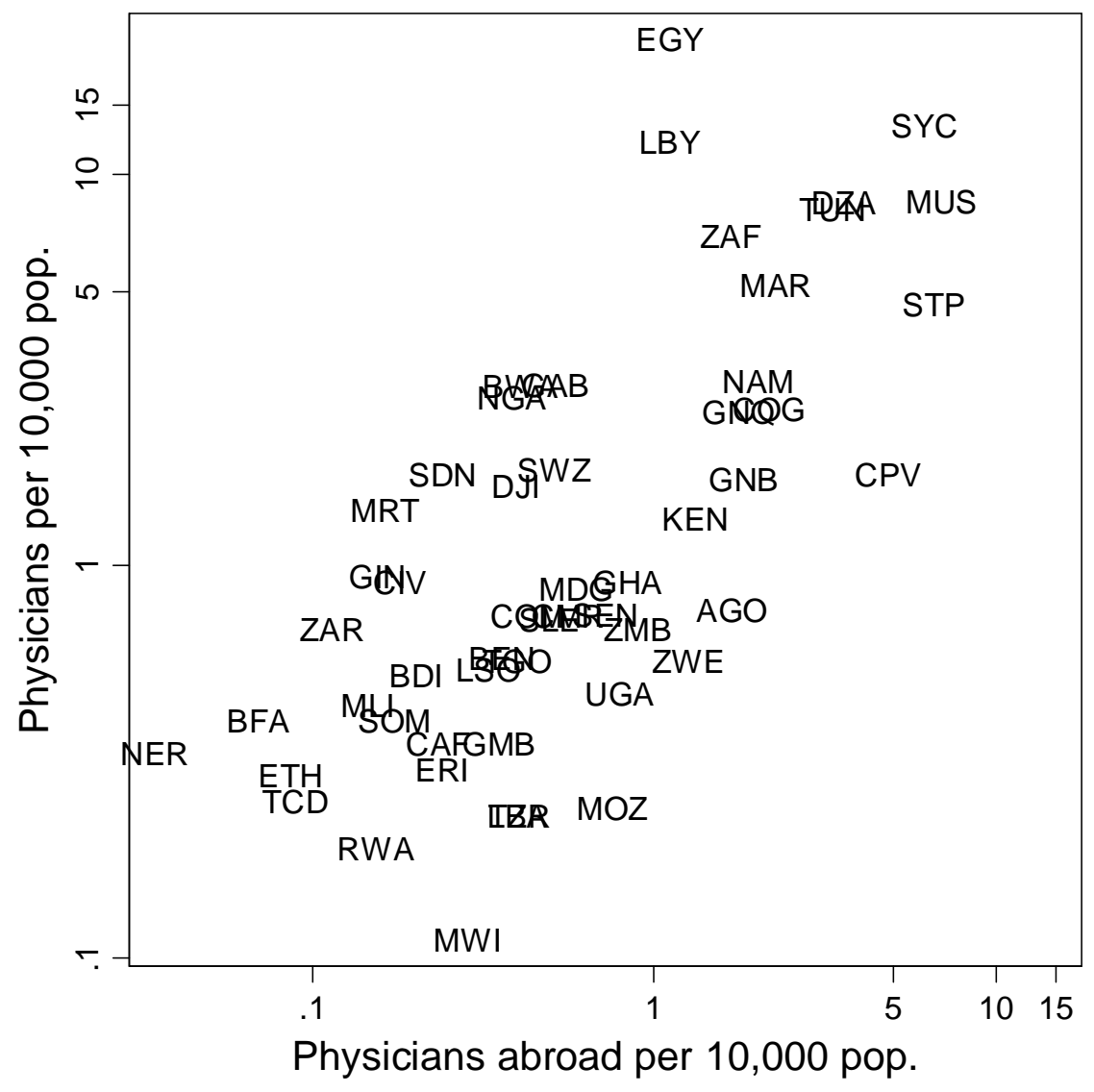


Figure 5: Simple correlation between child mortality rate and physicians abroad

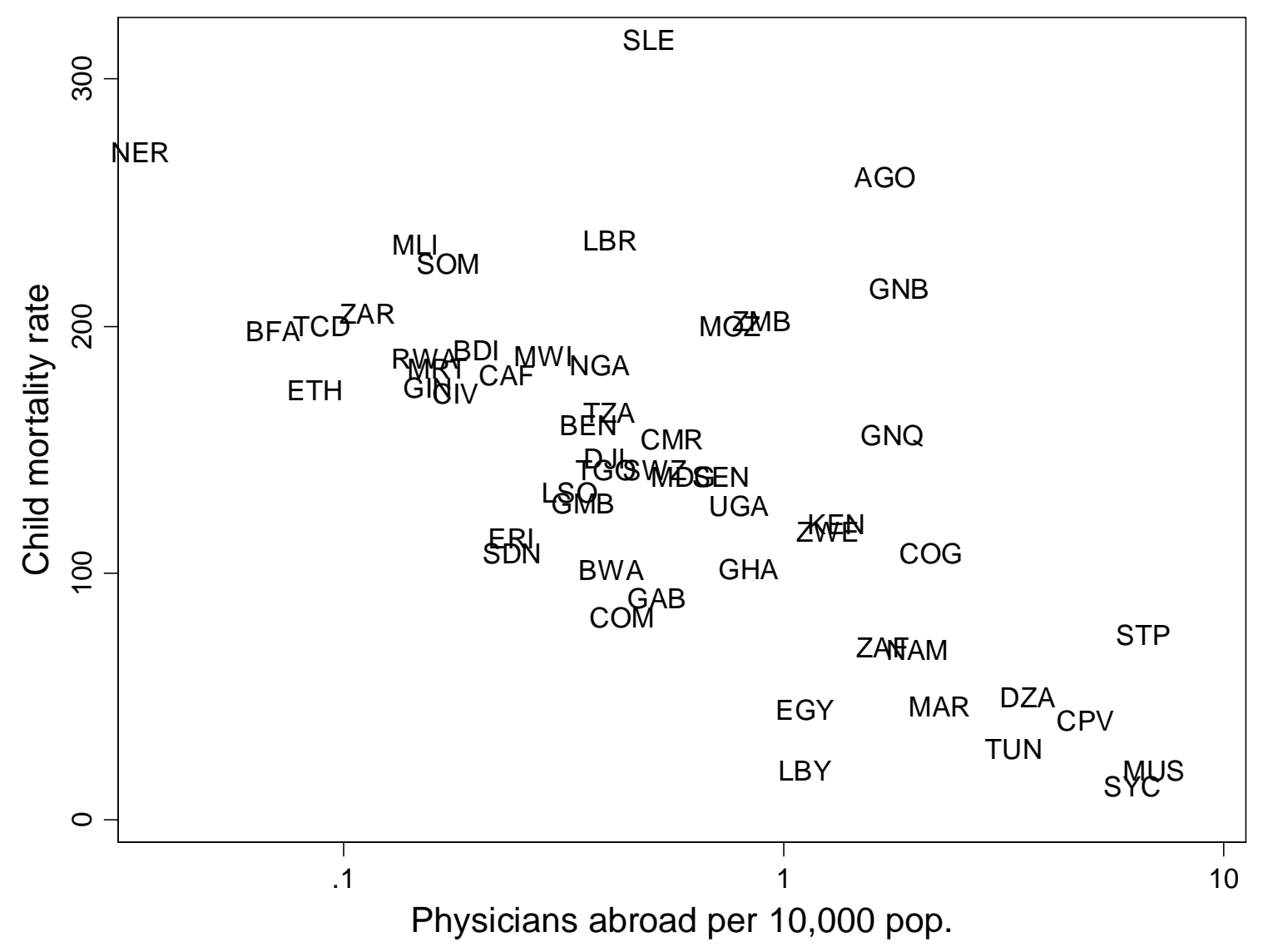


Table 1: Summary statistics

\begin{tabular}{|c|c|c|c|c|c|c|c|}
\hline \multirow[b]{2}{*}{ Variable } & \multirow[b]{2}{*}{$N$} & \multirow[b]{2}{*}{$\mu$} & \multirow[b]{2}{*}{$\sigma$} & \multirow[b]{2}{*}{ Min } & \multirow[b]{2}{*}{$\operatorname{Max}$} & \multicolumn{2}{|c|}{$\ln (\operatorname{var})$} \\
\hline & & & & & & $\mu$ & $\sigma$ \\
\hline $\begin{array}{l}\text { Physicians abroad } / 10,000 \text { pop. } \\
\text { (by country of birth) }\end{array}$ & 53 & 1.18 & 1.65 & 0.034 & 6.93 & -0.569 & 1.23 \\
\hline $\begin{array}{l}\text { Physicians abroad } / 10,000 \text { pop. } \\
\text { (by country of training)* }\end{array}$ & 53 & 0.249 & 0.598 & 0.000 & 3.72 & -2.69 & 1.65 \\
\hline Physician emigration/stock & 53 & 0.369 & 0.193 & 0.048 & 0.759 & -1.17 & 0.649 \\
\hline Physicians/10,000 pop & 53 & 2.51 & 4.07 & 0.110 & 22.2 & 0.088 & 1.24 \\
\hline Physician destination wage & 53 & 86,600 & 18,600 & 39,300 & 129,000 & 11.3 & 0.234 \\
\hline Physician destination GDP/cap. & 53 & 26,900 & 6,890 & 7,250 & 36,000 & 10.2 & 0.354 \\
\hline Nurses abroad/10,000 pop & 53 & 2.28 & 5.98 & 0.0528 & 38.2 & -0.302 & 1.35 \\
\hline Nurse emigration/stock & 53 & 0.164 & 0.165 & 0.00582 & 0.717 & -2.33 & 1.13 \\
\hline Nurses/10,000 pop & 53 & 11.5 & 15.2 & 0.880 & 86.2 & 1.82 & 1.09 \\
\hline Nurse destination wage & 53 & 36,300 & 5,320 & 24,300 & 47,000 & 10.5 & 0.148 \\
\hline Nurse destination GDP/cap. & 53 & 29,400 & 6,140 & 9,540 & 37,300 & 10.3 & 0.278 \\
\hline GDP per capita (2000 US\$) & 53 & 973 & 1,390 & 89.0 & 7,620 & 6.20 & 1.11 \\
\hline Primary school enrollment (\%) & 53 & 89.4 & 27.7 & 17.0 & 144 & 4.43 & 0.389 \\
\hline Land area, million $\mathrm{km}^{2}$ & 53 & 0.554 & 0.627 & 0.000450 & 2.382 & -1.74 & 2.11 \\
\hline Infant mortality/1000 & 53 & 90.5 & 39.4 & 9.90 & 180 & 4.37 & 0.605 \\
\hline Child mortality/1000 & 53 & 142 & 69.1 & 14.0 & 316 & 4.78 & 0.696 \\
\hline Measles vacc. (fraction <1) & 53 & 0.655 & 0.198 & 0.190 & 0.970 & -0.477 & 0.350 \\
\hline DPT vacc. (\% age $1-2)$ & 53 & 64.4 & 22.1 & 24.4 & 98.2 & 4.10 & 0.387 \\
\hline ARI prevalence $(\%<5)$ & 29 & 19.3 & 12.6 & 3.70 & 43.9 & 2.75 & 0.678 \\
\hline ARI treatment $(\%<5)$ & 29 & 40.8 & 17.4 & 14.2 & 69.1 & 3.61 & 0.473 \\
\hline Births attended (\%) & 46 & 53.6 & 22.3 & 5.60 & 98.5 & 3.87 & 0.532 \\
\hline Diarrhea prevalence $(\%<5)$ & 31 & 19.0 & 7.47 & 5.75 & 40.0 & 2.86 & 0.435 \\
\hline Diarrhea treatment $(\%<5)$ & 30 & 29.5 & 12.9 & 12.0 & 54.9 & 3.29 & 0.457 \\
\hline HIV prevalence (\% 15-49) & 42 & 8.26 & 9.69 & 0.100 & 38.2 & 1.38 & 1.45 \\
\hline$\%$ adults with HIV on ART & 35 & 9.19 & 19.9 & 0 & 100 & 1.33 & 1.24 \\
\hline Francophone & 53 & 0.396 & 0.494 & 0 & 1 & - & - \\
\hline Armed conflict 1970-99 & 53 & 0.434 & 0.500 & 0 & 1 & - & - \\
\hline
\end{tabular}

\footnotetext{
* The Bhargava and Docquier (2006) measure of physician emigration focuses on country of training for measuring emigration to principal destination countries, but uses country of citizenship or birth for other destination countries.
} 
Table 2: The effect of physicians abroad on domestic physician stock

\begin{tabular}{|c|c|c|c|c|c|c|c|}
\hline $\begin{array}{l}\text { Dependent variable: } \\
\text { ln Physicians/cap. }\end{array}$ & $\begin{array}{r}(1) \\
\text { OLS }\end{array}$ & $\begin{array}{r}(2) \\
\text { OLS } \\
\end{array}$ & $\begin{array}{r}(5) \\
2 \mathrm{SLS} \\
\end{array}$ & $\begin{array}{r}(6) \\
2 S L S \\
\end{array}$ & $\begin{array}{r}(9) \\
\text { 3SLS } \\
\end{array}$ & $\begin{array}{r}(10) \\
3 \text { SLS } \\
\end{array}$ & $\begin{array}{r}(11) \\
3 \text { SLS } \\
\end{array}$ \\
\hline $\begin{array}{l}\text { In Physicians abroad/cap. } \\
\text { (country of birth) }\end{array}$ & $\begin{array}{r}0.69 \\
(8.61)\end{array}$ & $\begin{array}{r}0.36 \\
(3.16)\end{array}$ & $\begin{array}{r}0.03 \\
(0.12)\end{array}$ & $\begin{array}{r}0.08 \\
(0.30)\end{array}$ & $\begin{array}{r}0.12 \\
(0.43)\end{array}$ & $\begin{array}{r}0.13 \\
(0.55)\end{array}$ & \\
\hline $\begin{array}{l}\text { In Physicians abroad/cap. } \\
\text { (country of training) }\end{array}$ & & & & & & & $\begin{array}{r}0.09 \\
(0.70)\end{array}$ \\
\hline ln GDP per capita & & $\begin{array}{r}0.75 \\
(6.26)\end{array}$ & $\begin{array}{r}0.94 \\
(4.09)\end{array}$ & $\begin{array}{r}0.91 \\
(4.13)\end{array}$ & $\begin{array}{r}0.73 \\
(4.17)\end{array}$ & $\begin{array}{r}0.92 \\
(5.50)\end{array}$ & $\begin{array}{r}0.91 \\
(6.71)\end{array}$ \\
\hline ln Primary enrollment & & $\begin{array}{l}-0.56 \\
(2.07)\end{array}$ & $\begin{array}{l}-0.21 \\
(0.71)\end{array}$ & $\begin{array}{l}-0.26 \\
(0.88)\end{array}$ & $\begin{array}{l}-0.46 \\
(1.18)\end{array}$ & $\begin{array}{l}-0.53 \\
(1.50)\end{array}$ & $\begin{array}{r}-0.29 \\
(1.06)\end{array}$ \\
\hline Conflict & & $\begin{array}{r}0.13 \\
(0.61)\end{array}$ & $\begin{array}{r}0.27 \\
(1.11)\end{array}$ & $\begin{array}{r}0.25 \\
(1.03)\end{array}$ & & $\begin{array}{r}0.22 \\
(1.01)\end{array}$ & $\begin{array}{l}0.18 \\
0.82\end{array}$ \\
\hline Constant & $\begin{array}{r}0.48 \\
(3.45)\end{array}$ & $\begin{array}{l}-1.91 \\
(1.33)\end{array}$ & $\begin{array}{r}-4.92 \\
(1.92)\end{array}$ & $\begin{array}{l}-4.47 \\
(1.77)\end{array}$ & $\begin{array}{l}-2.33 \\
(0.92)\end{array}$ & $\begin{array}{l}-3.33 \\
(1.44)\end{array}$ & $\begin{array}{l}-4.08 \\
(2.34)\end{array}$ \\
\hline$N$ & 53 & 53 & 53 & 53 & 53 & 53 & 51 \\
\hline $\begin{array}{l}\text { Adj. } R^{2} \\
p \text { (coeffs. zero) }\end{array}$ & $\begin{array}{r}0.465 \\
<0.001\end{array}$ & $\begin{array}{r}0.702 \\
<0.001\end{array}$ & $\begin{array}{r}0.646 \\
<0.001\end{array}$ & $\begin{array}{r}0.661 \\
<0.001\end{array}$ & $\begin{array}{r}0.666 \\
<0.001\end{array}$ & $\begin{array}{r}0.695 \\
<0.001\end{array}$ & $\begin{array}{r}0.705 \\
<0.001\end{array}$ \\
\hline
\end{tabular}

\begin{tabular}{|c|c|c|c|c|c|c|c|}
\hline $\begin{array}{l}\text { Dependent variable: } \\
\text { ln Physicians abroad/cap. }\end{array}$ & $\begin{array}{l}(3) \\
\text { OLS }\end{array}$ & $\begin{array}{l}(4) \\
\text { OLS }\end{array}$ & $\begin{array}{c}(7) \\
1 s t s t g .\end{array}$ & $\begin{array}{c}(8) \\
1 \text { st stg. }\end{array}$ & & & \\
\hline Francophone & $\begin{array}{l}-0.76 \\
(2.36)\end{array}$ & $\begin{array}{l}-0.90 \\
(2.35)\end{array}$ & $\begin{array}{l}-0.45 \\
(1.75)\end{array}$ & $\begin{array}{l}-0.24 \\
(0.78)\end{array}$ & $\begin{array}{l}-0.76 \\
(2.59)\end{array}$ & $\begin{array}{l}-0.51 \\
(1.83)\end{array}$ & $\begin{array}{l}-1.22 \\
(3.04)\end{array}$ \\
\hline ln Land area & $\begin{array}{l}-0.19 \\
(2.64)\end{array}$ & $\begin{array}{l}-0.17 \\
(2.28)\end{array}$ & $\begin{array}{l}-0.16 \\
(2.56)\end{array}$ & $\begin{array}{l}-0.16 \\
(2.75)\end{array}$ & $\begin{array}{l}-0.20 \\
(2.87)\end{array}$ & $\begin{array}{l}-0.17 \\
(3.20)\end{array}$ & $\begin{array}{l}-0.16 \\
(2.18)\end{array}$ \\
\hline ln Physician wage abroad & & $\begin{array}{l}-1.84 \\
(0.94)\end{array}$ & & $\begin{array}{r}1.39 \\
(0.90)\end{array}$ & & $\begin{array}{l}-0.05 \\
(0.03)\end{array}$ & $\begin{array}{r}1.65 \\
(0.81)\end{array}$ \\
\hline ln Destination GDP/cap. & & $\begin{array}{r}0.68 \\
(0.49)\end{array}$ & & $\begin{array}{l}-1.03 \\
(0.94)\end{array}$ & & $\begin{array}{l}-0.34 \\
(0.36)\end{array}$ & $\begin{array}{l}-0.91 \\
(0.64)\end{array}$ \\
\hline ln GDP/cap. & & & $\begin{array}{r}0.59 \\
(4.98)\end{array}$ & $\begin{array}{r}0.60 \\
(5.15)\end{array}$ & & $\begin{array}{r}0.68 \\
(6.44)\end{array}$ & $\begin{array}{r}0.78 \\
(5.25)\end{array}$ \\
\hline ln Primary enrollment & & & $\begin{array}{r}0.73 \\
(2.76)\end{array}$ & $\begin{array}{r}0.77 \\
(2.88)\end{array}$ & & & \\
\hline Conflict & & & $\begin{array}{r}0.59 \\
(2.33)\end{array}$ & $\begin{array}{r}0.62 \\
(2.46)\end{array}$ & & $\begin{array}{r}0.61 \\
(2.54)\end{array}$ & $\begin{array}{r}0.82 \\
(2.43)\end{array}$ \\
\hline Constant & $\begin{array}{l}-0.60 \\
(2.91)\end{array}$ & $\begin{array}{r}13.47 \\
(1.29)\end{array}$ & $\begin{array}{l}-7.80 \\
(6.27)\end{array}$ & $\begin{array}{r}-13.45 \\
(1.52)\end{array}$ & $\begin{array}{l}-0.61 \\
(2.70)\end{array}$ & $\begin{array}{l}-1.14 \\
(0.14)\end{array}$ & $\begin{array}{r}-17.12 \\
(1.48)\end{array}$ \\
\hline$N$ & 53 & 53 & 53 & 53 & 53 & 53 & 51 \\
\hline $\begin{array}{l}\text { Adj. } R^{2} \\
\text { Shea } R^{2} \text { of excl. instruments }\end{array}$ & 0.201 & 0.201 & $\begin{array}{l}0.628 \\
0.221\end{array}$ & $\begin{array}{l}0.636 \\
0.237\end{array}$ & 0.232 & 0.594 & 0.554 \\
\hline$p$ (coeffs. zero) & 0.006 & 0.027 & $<0.001$ & $<0.001$ & $<0.001$ & $<0.001$ & $<0.001$ \\
\hline$F$ statistic & 5.64 & 3.02 & 22.65 & 17.00 & & & \\
\hline Anderson CC test, p-value & & & 0.001 & 0.006 & & & \\
\hline Cragg-Donald Statistic & & & 6.66 & 3.49 & & & \\
\hline Anderson-Rubin test, p-value & & & 0.974 & 0.615 & & & \\
\hline Hansen J-test, p-value & & & 0.808 & 0.306 & & & \\
\hline
\end{tabular}

Abs. val. of robust t-statistics in parentheses. "Anderson CC" is Anderson's canonical correlation test for weak instruments. Columns 7 and 8 are the first-stage regressions for columns 5 and 6 . For 3SLS regressions, p(all coefficients zero) is $\chi^{2}$ test. For others, F-test. 
Table 3: The effect of professional nurses abroad on domestic professional nurse stock

\begin{tabular}{|c|c|c|c|c|c|c|}
\hline $\begin{array}{l}\text { Dependent variable: } \\
\text { ln Nurses/cap. }\end{array}$ & $\begin{aligned}(1) \\
\text { OLS }\end{aligned}$ & $\begin{array}{r}(2) \\
\text { OLS }\end{array}$ & $\begin{array}{r}(5) \\
2 S L S\end{array}$ & $\begin{array}{r}(6) \\
2 \text { SLS }\end{array}$ & $\begin{array}{r}(9) \\
\text { 3SLS }\end{array}$ & $\begin{array}{r}(10) \\
3 \text { 3LS }\end{array}$ \\
\hline $\begin{array}{l}\text { ln Nurses abroad/cap. } \\
\text { (country of birth) }\end{array}$ & $\begin{array}{r}0.34 \\
(3.56)\end{array}$ & $\begin{array}{r}0.09 \\
(1.02)\end{array}$ & $\begin{array}{r}0.07 \\
(0.46)\end{array}$ & $\begin{array}{r}0.07 \\
(0.49)\end{array}$ & $\begin{array}{r}0.07 \\
(0.46)\end{array}$ & $\begin{array}{r}0.07 \\
(0.52)\end{array}$ \\
\hline ln GDP per capita & & $\begin{array}{r}0.78 \\
(7.25)\end{array}$ & $\begin{array}{r}0.79 \\
(7.00)\end{array}$ & $\begin{array}{r}0.79 \\
(7.01)\end{array}$ & $\begin{array}{r}0.75 \\
(7.12)\end{array}$ & $\begin{array}{r}0.79 \\
(7.37)\end{array}$ \\
\hline ln Primary enrollment & & $\begin{array}{l}-0.26 \\
(0.90)\end{array}$ & $\begin{array}{l}-0.22 \\
(0.83)\end{array}$ & $\begin{array}{r}-0.22 \\
(0.84)\end{array}$ & $\begin{array}{l}-0.27 \\
(0.83)\end{array}$ & $\begin{array}{l}-0.25 \\
(0.78)\end{array}$ \\
\hline Conflict & & $\begin{array}{r}0.19 \\
(0.98)\end{array}$ & $\begin{array}{r}0.20 \\
(1.07)\end{array}$ & $\begin{array}{r}0.20 \\
(1.09)\end{array}$ & & $\begin{array}{r}0.20 \\
(0.99)\end{array}$ \\
\hline Constant & $\begin{array}{r}1.93 \\
(13.4)\end{array}$ & $\begin{array}{l}-1.91 \\
(1.37)\end{array}$ & $\begin{array}{l}-2.15 \\
(1.49)\end{array}$ & $\begin{array}{l}-2.15 \\
(1.52)\end{array}$ & $\begin{array}{l}-1.60 \\
(1.00)\end{array}$ & $\begin{array}{l}-2.05 \\
(1.31)\end{array}$ \\
\hline$N$ & 53 & 53 & 53 & 53 & 53 & 53 \\
\hline Adj. $R^{2}$ & 0.157 & 0.595 & 0.594 & 0.594 & 0.617 & 0.625 \\
\hline$p($ coeffs. zero $)$ & $<0.001$ & $<0.001$ & $<0.001$ & $<0.001$ & $<0.001$ & $<0.001$ \\
\hline $\begin{array}{l}\text { Dependent variable: } \\
\text { ln Nurses abroad/cap. }\end{array}$ & $\begin{array}{l}(3) \\
\text { OLS }\end{array}$ & $\begin{array}{l}(4) \\
\text { OLS }\end{array}$ & $\begin{array}{c}(7) \\
1 s t \text { stg. }\end{array}$ & $\begin{array}{c}(8) \\
1 s t \text { stg. }\end{array}$ & & \\
\hline Francophone & $\begin{array}{l}-0.66 \\
(2.09)\end{array}$ & $\begin{array}{l}-1.04 \\
(1.78)\end{array}$ & $\begin{array}{l}-0.36 \\
(1.28)\end{array}$ & $\begin{array}{l}-0.60 \\
(1.21)\end{array}$ & $\begin{array}{l}-0.63 \\
(2.09)\end{array}$ & $\begin{array}{l}-0.71 \\
(1.47)\end{array}$ \\
\hline ln Land area & $\begin{array}{r}-0.33 \\
(4.11)\end{array}$ & $\begin{array}{l}-0.33 \\
(4.10)\end{array}$ & $\begin{array}{l}-0.33 \\
(4.60)\end{array}$ & $\begin{array}{l}-0.33 \\
(4.61)\end{array}$ & $\begin{array}{l}-0.33 \\
(4.73)\end{array}$ & $\begin{array}{l}-0.36 \\
(5.47)\end{array}$ \\
\hline ln Nurse wage abroad & & $\begin{array}{l}-1.91 \\
(0.75)\end{array}$ & & $\begin{array}{l}-1.16 \\
(0.59)\end{array}$ & & $\begin{array}{l}-1.26 \\
(0.63)\end{array}$ \\
\hline ln Destination GDP/cap. & & $\begin{array}{r}0.71 \\
(0.61)\end{array}$ & & $\begin{array}{r}0.60 \\
(0.65)\end{array}$ & & $\begin{array}{r}0.56 \\
(0.61)\end{array}$ \\
\hline ln GDP per capita & & & $\begin{array}{r}0.37 \\
(2.60)\end{array}$ & $\begin{array}{r}0.36 \\
(2.52)\end{array}$ & & $\begin{array}{r}0.48 \\
(3.95)\end{array}$ \\
\hline Conflict & & & $\begin{array}{r}0.78 \\
(2.67)\end{array}$ & $\begin{array}{r}0.78 \\
(2.69)\end{array}$ & & $\begin{array}{r}0.78 \\
(2.80)\end{array}$ \\
\hline Constant & $\begin{array}{l}-0.61 \\
(2.71)\end{array}$ & $\begin{array}{r}12.29 \\
(0.71)\end{array}$ & $\begin{array}{r}-6.80 \\
(4.74)\end{array}$ & $\begin{array}{l}-0.64 \\
(0.04)\end{array}$ & $\begin{array}{l}-0.64 \\
(2.70)\end{array}$ & $\begin{array}{r}3.45 \\
(0.25)\end{array}$ \\
\hline$N$ & 53 & 53 & 53 & 53 & 53 & 53 \\
\hline $\begin{array}{l}\text { Adj. } R^{2} \\
\text { Shea } R^{2} \text { of excl. instruments }\end{array}$ & 0.338 & 0.319 & $\begin{array}{l}0.570 \\
0.373\end{array}$ & $\begin{array}{l}0.573 \\
0.378\end{array}$ & 0.363 & 0.538 \\
\hline$p$ (coeffs. zero $)$ & $<0.001$ & 0.001 & $<0.001$ & $<0.001$ & $<0.001$ & $<0.001$ \\
\hline$F$ statistic & 11.16 & 5.70 & 13.81 & 10.18 & & \\
\hline Anderson $\mathrm{CC}$ test, $\mathrm{p}$-value & & & $<0.001$ & $<0.001$ & & \\
\hline Cragg-Donald Statistic & & & 13.96 & 6.84 & & \\
\hline Anderson-Rubin test, p-value & & & 0.389 & 0.047 & & \\
\hline Hansen J-test, p-value & & & 0.151 & 0.088 & & \\
\hline
\end{tabular}

Absolute value of robust t-statistics in parentheses. "Anderson CC" is Anderson's canonical correlation test for weak instruments. Columns 7 and 8 are the first-stage regressions for columns 5 and 6 . For 3SLS regressions, p(all coefficients zero) is $\chi^{2}$ test. For others, F-test. 
Table 4: The effect of physicians abroad on child mortality

\begin{tabular}{|c|c|c|c|c|c|c|c|}
\hline $\begin{array}{l}\text { Dependent variable: } \\
\text { ln Child mortality rate }\end{array}$ & $\begin{array}{l}(1) \\
\text { OLS }\end{array}$ & $\begin{array}{c}(2) \\
\text { OLS }\end{array}$ & $\begin{array}{c}(5) \\
2 \mathrm{SLS}\end{array}$ & $\begin{array}{c}(6) \\
2 \mathrm{SLS}\end{array}$ & $\begin{array}{c}(9) \\
3 \mathrm{SLS}\end{array}$ & $\begin{array}{c}(10) \\
3 \mathrm{SLS}\end{array}$ & $\begin{array}{c}(11) \\
3 \mathrm{SLS}\end{array}$ \\
\hline $\begin{array}{l}\text { In Physicians abroad/cap. } \\
\text { (country of birth) }\end{array}$ & $\begin{array}{l}-0.39 \\
(6.19)\end{array}$ & $\begin{array}{l}-0.21 \\
(3.34)\end{array}$ & $\begin{array}{l}-0.30 \\
(2.20)\end{array}$ & $\begin{array}{l}-0.26 \\
(2.05)\end{array}$ & $\begin{array}{l}-0.28 \\
(1.98)\end{array}$ & $\begin{array}{l}-0.25 \\
(1.86)\end{array}$ & \\
\hline $\begin{array}{l}\text { In Physicians abroad/cap. } \\
\text { (country of training) }\end{array}$ & & & & & & & $\begin{array}{l}-0.14 \\
(2.03)\end{array}$ \\
\hline ln GDP per capita & & $\begin{array}{l}-0.34 \\
(3.81)\end{array}$ & $\begin{array}{l}-0.28 \\
(2.79)\end{array}$ & $\begin{array}{l}-0.31 \\
(3.14)\end{array}$ & $\begin{array}{l}-0.32 \\
(3.16)\end{array}$ & $\begin{array}{l}-0.31 \\
(3.08)\end{array}$ & $\begin{array}{l}-0.36 \\
(4.74)\end{array}$ \\
\hline In Primary enrollment & & $\begin{array}{r}0.07 \\
(0.65)\end{array}$ & $\begin{array}{r}0.17 \\
(0.91)\end{array}$ & $\begin{array}{r}0.12 \\
(0.74)\end{array}$ & $\begin{array}{r}0.12 \\
(0.53)\end{array}$ & $\begin{array}{r}0.08 \\
(0.39)\end{array}$ & $\begin{array}{l}-0.04 \\
(0.21)\end{array}$ \\
\hline Conflict & & $\begin{array}{r}0.04 \\
(0.33)\end{array}$ & $\begin{array}{r}0.08 \\
(0.55)\end{array}$ & $\begin{array}{r}0.07 \\
(0.46)\end{array}$ & $\begin{array}{r}0.04 \\
(0.33)\end{array}$ & $\begin{array}{r}0.06 \\
(0.46)\end{array}$ & $\begin{array}{r}0.09 \\
(0.74)\end{array}$ \\
\hline Constant & $\begin{array}{r}4.56 \\
(46.99)\end{array}$ & $\begin{array}{r}6.40 \\
(7.55)\end{array}$ & $\begin{array}{r}5.60 \\
(4.06)\end{array}$ & $\begin{array}{r}5.96 \\
(4.62)\end{array}$ & $\begin{array}{r}6.09 \\
(4.17)\end{array}$ & $\begin{array}{r}6.13 \\
(4.36)\end{array}$ & $\begin{array}{r}6.74 \\
(6.65)\end{array}$ \\
\hline$N$ & 53 & 53 & 53 & 53 & 53 & 53 & 51 \\
\hline Adj. $R^{2}$ & 0.472 & 0.629 & 0.617 & 0.625 & 0.648 & 0.655 & 0.704 \\
\hline$p($ coeffs. zero $)$ & $<0.001$ & $<0.001$ & $<0.001$ & $<0.001$ & $<0.001$ & $<0.001$ & $<0.001$ \\
\hline Dependent variable: & $(3)$ & $(4)$ & $(7)$ & $(8)$ & & & \\
\hline ln Physicians abroad/cap. & OLS & OLS & 1st stg. & 1st stg. & & & \\
\hline Francophone & $\begin{array}{l}-0.76 \\
(2.36)\end{array}$ & $\begin{array}{l}-0.90 \\
(2.35)\end{array}$ & $\begin{array}{l}-0.49 \\
(1.75)\end{array}$ & $\begin{array}{l}-0.24 \\
(0.78)\end{array}$ & $\begin{array}{l}-0.72 \\
(2.38)\end{array}$ & $\begin{array}{l}-0.41 \\
(1.36)\end{array}$ & $\begin{array}{l}-1.06 \\
(2.48)\end{array}$ \\
\hline ln Land area & $\begin{array}{l}-0.19 \\
(2.64)\end{array}$ & $\begin{array}{l}-0.17 \\
(2.28)\end{array}$ & $\begin{array}{l}-0.16 \\
(2.56)\end{array}$ & $\begin{array}{l}-0.16 \\
(2.75)\end{array}$ & $\begin{array}{l}-0.20 \\
(2.83)\end{array}$ & $\begin{array}{l}-0.19 \\
(3.35)\end{array}$ & $\begin{array}{r}0.16 \\
(1.99)\end{array}$ \\
\hline ln Physician wage abroad & & $\begin{array}{l}-1.84 \\
(0.94)\end{array}$ & & $\begin{array}{r}1.39 \\
(0.90)\end{array}$ & & $\begin{array}{r}0.67 \\
(0.43)\end{array}$ & $\begin{array}{r}2.71 \\
(1.24)\end{array}$ \\
\hline In Destination GDP/cap. & & $\begin{array}{r}0.68 \\
(0.49)\end{array}$ & & $\begin{array}{l}-1.03 \\
(0.94)\end{array}$ & & $\begin{array}{l}-0.61 \\
(0.58)\end{array}$ & $\begin{array}{l}-1.60 \\
(1.04)\end{array}$ \\
\hline ln GDP/cap. & & & $\begin{array}{r}0.59 \\
(4.98)\end{array}$ & $\begin{array}{r}0.60 \\
(5.15)\end{array}$ & & $\begin{array}{r}0.70 \\
(6.61)\end{array}$ & $\begin{array}{r}0.80 \\
(5.35)\end{array}$ \\
\hline ln Primary enrollment & & & $\begin{array}{r}0.73 \\
(2.76)\end{array}$ & $\begin{array}{r}0.77 \\
(2.88)\end{array}$ & & & \\
\hline Conflict & & & $\begin{array}{r}0.59 \\
(2.33)\end{array}$ & $\begin{array}{r}0.62 \\
(2.46)\end{array}$ & & $\begin{array}{r}0.62 \\
(2.58)\end{array}$ & $\begin{array}{r}0.82 \\
(2.42)\end{array}$ \\
\hline Constant & $\begin{array}{l}-0.60 \\
(2.91)\end{array}$ & $\begin{array}{r}13.47 \\
(1.29)\end{array}$ & $\begin{array}{l}-7.80 \\
(6.27)\end{array}$ & $\begin{array}{r}-13.45 \\
(1.52)\end{array}$ & $\begin{array}{r}0.63 \\
(2.69)\end{array}$ & $\begin{array}{l}-6.79 \\
(0.80)\end{array}$ & $\begin{array}{r}-22.49 \\
(1.80)\end{array}$ \\
\hline$N$ & 53 & 53 & 53 & 53 & 53 & 53 & 51 \\
\hline Adj. $R^{2}$ & 0.201 & 0.201 & 0.628 & 0.636 & 0.232 & 0.596 & 0.556 \\
\hline Shea $R^{2}$ of excl. instruments & & & 0.221 & 0.237 & & & \\
\hline$p($ coeffs. zero $)$ & 0.006 & 0.027 & $<0.001$ & $<0.001$ & $<0.001$ & $<0.001$ & $<0.001$ \\
\hline$F$ statistic & 5.64 & 3.02 & 22.65 & 17.00 & & & \\
\hline Anderson CC test, p-value & & & 0.001 & 0.006 & & & \\
\hline Cragg-Donald Statistic & & & 6.66 & 3.49 & & & \\
\hline Anderson-Rubin test, p-value & & & 0.086 & 0.053 & & & \\
\hline Hansen J-test, p-value & & & 0.204 & 0.060 & & & \\
\hline
\end{tabular}

Absolute value of robust t-statistics in parentheses. "Anderson CC" is Anderson's canonical correlation test for weak instruments. Columns 7 and 8 are the first-stage regressions for columns 5 and 6 . For 3SLS regressions, p(all coefficients zero) is $\chi^{2}$ test. For others, F-test. 
Table 5: The effect of professional nurses abroad on child mortality

\begin{tabular}{lrrrrrr} 
Dependent variable: & $(1)$ & $(2)$ & \multicolumn{1}{c}{$(5)$} & \multicolumn{1}{c}{$(6)$} & \multicolumn{1}{c}{$(9)$} & \multicolumn{1}{c}{$(10)$} \\
ln Child mortality rate & OLS & OLS & 2SLS & 2SLS & 3SLS & 3SLS \\
\cline { 2 - 7 } & & & & & & \\
ln Nurses abroad/cap. & -0.27 & -0.13 & -0.20 & -0.22 & -0.19 & -0.20 \\
$\quad$ (country of birth) & $(3.78)$ & $(2.22)$ & $(2.62)$ & $(2.92)$ & $(2.24)$ & $(2.37)$ \\
ln GDP per capita & & -0.41 & -0.39 & -0.38 & -0.42 & 0.37 \\
& & $(5.08)$ & $(4.76)$ & $(4.54)$ & $(6.10)$ & $(5.34)$ \\
ln Primary enrollment & & 0.01 & 0.11 & 0.13 & 0.05 & 0.02 \\
& & $(0.15)$ & $(0.88)$ & $(1.07)$ & $(0.24)$ & $(0.11)$ \\
Conflict & & 0.00 & 0.03 & 0.04 & -0.03 & 0.03 \\
& & $(0.01)$ & $(0.21)$ & 0.26 & $(0.21)$ & $(0.22)$ \\
Constant & 4.70 & 7.24 & 6.65 & 6.50 & 7.10 & 6.91 \\
& $(51.19)$ & $(9.84)$ & $(7.65)$ & $(7.27)$ & $(7.11)$ & $(6.94)$ \\
$N$ & & & & & & \\
Adj. $R^{2}$ & 53 & 53 & 53 & 53 & 53 & 53 \\
& 0.269 & 0.603 & 0.589 & 0.582 & 0.619 & 0.617
\end{tabular}

$p$ (coeffs. zero)

\begin{tabular}{|c|c|c|c|c|c|c|}
\hline $\begin{array}{l}\text { Dependent variable: } \\
\text { ln Nurses abroad/cap. }\end{array}$ & $\begin{array}{l}(3) \\
\text { OLS }\end{array}$ & $\begin{array}{l}(4) \\
\text { OLS }\end{array}$ & $\begin{array}{c}(7) \\
1 \text { st stg. }\end{array}$ & $\begin{array}{c}(8) \\
1 \text { st stg. }\end{array}$ & & \\
\hline Francophone & $\begin{array}{l}-0.66 \\
(2.09)\end{array}$ & $\begin{array}{l}-1.04 \\
(1.78)\end{array}$ & $\begin{array}{l}-0.36 \\
(1.28)\end{array}$ & $\begin{array}{l}-0.60 \\
(1.21)\end{array}$ & $\begin{array}{l}-0.63 \\
(2.10)\end{array}$ & $\begin{array}{l}-0.84 \\
(1.80)\end{array}$ \\
\hline ln Land area & $\begin{array}{l}-0.33 \\
(4.11)\end{array}$ & $\begin{array}{l}-0.33 \\
(4.10)\end{array}$ & $\begin{array}{l}-0.33 \\
(4.60)\end{array}$ & $\begin{array}{l}-0.33 \\
(4.61)\end{array}$ & $\begin{array}{r}-0.33 \\
(4.72)\end{array}$ & $\begin{array}{r}-0.36 \\
(5.53)\end{array}$ \\
\hline ln Nurse wage abroad & & $\begin{array}{l}-1.91 \\
(0.75)\end{array}$ & & $\begin{array}{l}-1.16 \\
(0.59)\end{array}$ & & $\begin{array}{l}-1.99 \\
(1.03)\end{array}$ \\
\hline In Destination GDP/cap. & & $\begin{array}{r}0.71 \\
(0.61)\end{array}$ & & $\begin{array}{r}0.60 \\
(0.65)\end{array}$ & & $\begin{array}{r}1.00 \\
(1.11)\end{array}$ \\
\hline $\ln$ GDP/cap. & & & $\begin{array}{r}0.37 \\
(2.60)\end{array}$ & $\begin{array}{r}0.36 \\
(2.52)\end{array}$ & & $\begin{array}{r}0.48 \\
(3.95)\end{array}$ \\
\hline ln Primary enrollment & & & $\begin{array}{r}0.78 \\
(2.00)\end{array}$ & $\begin{array}{r}0.78 \\
(1.93)\end{array}$ & & \\
\hline Conflict & & & $\begin{array}{r}0.78 \\
(2.00)\end{array}$ & $\begin{array}{r}0.78 \\
(2.69)\end{array}$ & & $\begin{array}{r}0.79 \\
(2.82)\end{array}$ \\
\hline Constant & $\begin{array}{l}-0.61 \\
(2.71)\end{array}$ & $\begin{array}{r}12.29 \\
(0.71)\end{array}$ & $\begin{array}{r}-6.80 \\
(4.74)\end{array}$ & $\begin{array}{l}-0.64 \\
(0.04)\end{array}$ & $\begin{array}{r}-0.63 \\
(2.71)\end{array}$ & $\begin{array}{r}6.76 \\
(0.50)\end{array}$ \\
\hline$N$ & 53 & 53 & 53 & 53 & 53 & 53 \\
\hline Adj. $R^{2}$ & 0.338 & 0.319 & 0.570 & 0.573 & 0.363 & 0.536 \\
\hline $\begin{array}{l}p \text { (coeffs. zero }) \\
F \text { statistic }\end{array}$ & & & $\begin{array}{r}<0.001 \\
14.28\end{array}$ & $\begin{array}{r}<0.001 \\
10.18\end{array}$ & & \\
\hline Anderson CC test, p-value & & & $<0.001$ & $<0.001$ & & \\
\hline Cragg-Donald Statistic & & & 13.96 & 6.84 & & \\
\hline Anderson-Rubin test, $\mathrm{p}$-value & & & 0.086 & 0.065 & & \\
\hline Hansen J-test, p-value & & & 0.562 & 0.451 & & \\
\hline
\end{tabular}

Absolute value of robust t-statistics in parentheses. "Anderson CC" is Anderson's canonical correlation test for weak instruments. The 2SLS regression in column 5 uses the exogenous instruments in column 3, and the 2SLS regression in column 6 uses the expanded instrument set in column 4. For 3SLS regressions, p(all coefficients zero) is $\chi^{2}$ test. For others, F-test. 
Table 6: The effect of physicians abroad on other public health indicators

\begin{tabular}{|c|c|c|c|c|c|}
\hline Dependent variable: & $\begin{array}{c}(1) \\
\ln \\
\text { IMR }\end{array}$ & $\begin{array}{c}(2) \\
\ln \\
\text { Measles }\end{array}$ & $\begin{array}{c}(3) \\
\ln \\
\text { DPT }\end{array}$ & $\begin{array}{c}(4) \\
\text { ln ARI } \\
\text { prev. }\end{array}$ & $\begin{array}{c}(5) \\
\ln \text { ARI } \\
\text { treat. }\end{array}$ \\
\hline $\begin{array}{l}\text { In Physicians abroad/cap. } \\
\text { (country of birth) }\end{array}$ & $\begin{array}{l}-0.22 \\
(1.74)\end{array}$ & $\begin{array}{r}0.12 \\
(1.08)\end{array}$ & $\begin{array}{r}0.20 \\
(1.78)\end{array}$ & $\begin{array}{l}-0.26 \\
(1.57)\end{array}$ & $\begin{array}{r}0.23 \\
(2.15)\end{array}$ \\
\hline ln GDP per capita & $\begin{array}{l}-0.25 \\
(2.70)\end{array}$ & $\begin{array}{l}-0.05 \\
(0.61)\end{array}$ & $\begin{array}{l}-0.08 \\
(0.95)\end{array}$ & $\begin{array}{r}0.07 \\
(0.43)\end{array}$ & $\begin{array}{r}0.02 \\
(0.16)\end{array}$ \\
\hline ln Primary enrollment & $\begin{array}{r}0.06 \\
(0.31)\end{array}$ & $\begin{array}{r}0.23 \\
(1.30)\end{array}$ & $\begin{array}{r}0.29 \\
(1.71)\end{array}$ & $\begin{array}{r}1.15 \\
(2.43)\end{array}$ & $\begin{array}{l}-0.33 \\
(1.07)\end{array}$ \\
\hline Conflict & $\begin{array}{r}0.06 \\
(0.52)\end{array}$ & $\begin{array}{l}-0.02 \\
(0.15)\end{array}$ & $\begin{array}{l}-0.17 \\
(1.60)\end{array}$ & $\begin{array}{r}0.20 \\
(0.82)\end{array}$ & $\begin{array}{l}-0.01 \\
(0.06)\end{array}$ \\
\hline Constant & $\begin{array}{r}5.48 \\
(4.19)\end{array}$ & $\begin{array}{l}-1.11 \\
(0.98)\end{array}$ & $\begin{array}{r}3.46 \\
(3.09)\end{array}$ & $\begin{array}{l}-3.07 \\
(1.37)\end{array}$ & $\begin{array}{r}5.21 \\
(3.54)\end{array}$ \\
\hline $\begin{array}{l}N \\
\text { Adj. } R^{2} \\
p(\text { coeffs. zero })\end{array}$ & $\begin{array}{r}53 \\
0.606 \\
<0.001\end{array}$ & $\begin{array}{r}53 \\
0.118 \\
0.018\end{array}$ & $\begin{array}{r}53 \\
0.279 \\
<0.001\end{array}$ & $\begin{array}{r}29 \\
0.255 \\
0.128\end{array}$ & $\begin{array}{r}29 \\
0.323 \\
0.279\end{array}$ \\
\hline \multicolumn{6}{|c|}{$\begin{array}{l}\text { Dependent variable: } \\
\text { ln Physicians abroad/cap. }\end{array}$} \\
\hline Francophone & $\begin{array}{r}-0.43 \\
(1.41)\end{array}$ & $\begin{array}{r}-0.47 \\
(1.59)\end{array}$ & $\begin{array}{l}-0.51 \\
(1.78)\end{array}$ & $\begin{array}{r}-0.96 \\
(2.97)\end{array}$ & $\begin{array}{l}-0.91 \\
(2.88)\end{array}$ \\
\hline ln Land area & $\begin{array}{l}-0.19 \\
(3.40)\end{array}$ & $\begin{array}{l}-0.18 \\
(3.17)\end{array}$ & $\begin{array}{l}-0.18 \\
(3.34)\end{array}$ & $\begin{array}{r}-0.17 \\
(2.04)\end{array}$ & $\begin{array}{l}-0.16 \\
(2.04)\end{array}$ \\
\hline ln Physician wage abroad & $\begin{array}{r}0.55 \\
(0.36)\end{array}$ & $\begin{array}{r}0.63 \\
(0.42)\end{array}$ & $\begin{array}{r}0.20 \\
(0.14)\end{array}$ & $\begin{array}{r}0.95 \\
(0.53)\end{array}$ & $\begin{array}{r}0.79 \\
(0.46)\end{array}$ \\
\hline ln Destination GDP/cap. & $\begin{array}{r}-0.50 \\
(0.48)\end{array}$ & $\begin{array}{l}-0.60 \\
(0.59)\end{array}$ & $\begin{array}{l}-0.30 \\
(0.30)\end{array}$ & $\begin{array}{l}-2.33 \\
(1.55)\end{array}$ & $\begin{array}{l}-2.44 \\
(1.64)\end{array}$ \\
\hline $\ln$ GDP/cap. & $\begin{array}{r}0.70 \\
(6.60)\end{array}$ & $\begin{array}{r}0.70 \\
(6.59)\end{array}$ & $\begin{array}{r}0.69 \\
(6.55)\end{array}$ & $\begin{array}{r}0.41 \\
(2.32)\end{array}$ & $\begin{array}{r}0.39 \\
(2.25)\end{array}$ \\
\hline Conflict & $\begin{array}{r}0.62 \\
(2.58)\end{array}$ & $\begin{array}{r}0.60 \\
(2.49)\end{array}$ & $\begin{array}{r}0.60 \\
(2.53)\end{array}$ & $\begin{array}{r}0.22 \\
(0.75)\end{array}$ & $\begin{array}{r}0.21 \\
(0.73)\end{array}$ \\
\hline Constant & $\begin{array}{l}-6.57 \\
(0.78)\end{array}$ & $\begin{array}{l}-6.40 \\
(0.77)\end{array}$ & $\begin{array}{l}-4.46 \\
(0.55)\end{array}$ & $\begin{array}{r}9.82 \\
(0.88)\end{array}$ & $\begin{array}{r}12.71 \\
(1.16)\end{array}$ \\
\hline$N$ & 53 & 53 & 53 & 29 & 29 \\
\hline $\begin{array}{l}\text { Adj. } R^{2} \\
p(\text { coeffs. zero) }\end{array}$ & $\begin{array}{r}0.596 \\
<0.001\end{array}$ & $\begin{array}{r}0.596 \\
<0.001\end{array}$ & $\begin{array}{r}0.596 \\
<0.001\end{array}$ & $\begin{array}{r}0.616 \\
<0.001\end{array}$ & $\begin{array}{r}0.614 \\
<0.001\end{array}$ \\
\hline
\end{tabular}

Each column shows a single 3SLS regression. Absolute value of robust t-statistics in parentheses. 'IMR' is infant mortality rate per thousand live births. 'Measles' is the fraction of children under age 1 vaccinated against measles. 'DPT' is the percentage of children 12-23 months vaccinated against DPT. 'ARI prev.' is the prevalence of acute respiratory infections in children under 5 over a two week period requiring medical care, and 'ARI treat' is the \% of those who saw a professional health care provider. 
Table 7: The effect of physicians abroad on other public health indicators (continued)

\begin{tabular}{|c|c|c|c|c|c|}
\hline Dependent variable: & $\begin{array}{c}(1) \\
\text { ln Births } \\
\text { attend. }\end{array}$ & $\begin{array}{c}(2) \\
\text { ln Diarr. } \\
\text { prev. }\end{array}$ & $\begin{array}{c}(3) \\
\text { ln Diarr. } \\
\text { treat. }\end{array}$ & $\begin{array}{c}(4) \\
\text { ln HIV } \\
\text { prev. }\end{array}$ & $\begin{array}{c}(5) \\
\text { ln HIV } \\
\text { treat. }\end{array}$ \\
\hline $\begin{array}{l}\text { In Physicians abroad/cap. } \\
\text { (country of birth) }\end{array}$ & $\begin{array}{r}0.10 \\
(0.90)\end{array}$ & $\begin{array}{l}-0.16 \\
(1.02)\end{array}$ & $\begin{array}{r}0.79 \\
(2.49)\end{array}$ & $\begin{array}{r}1.41 \\
(0.63)\end{array}$ & $\begin{array}{r}0.54 \\
(0.78)\end{array}$ \\
\hline ln GDP per capita & $\begin{array}{r}0.23 \\
(2.62)\end{array}$ & $\begin{array}{l}-0.17 \\
(1.80)\end{array}$ & $\begin{array}{l}-0.35 \\
(1.84)\end{array}$ & $\begin{array}{l}-1.24 \\
(0.87)\end{array}$ & $\begin{array}{r}0.08 \\
(0.15)\end{array}$ \\
\hline ln Primary enrollment & $\begin{array}{r}0.14 \\
(0.75)\end{array}$ & $\begin{array}{l}-0.03 \\
(0.18)\end{array}$ & $\begin{array}{l}-0.10 \\
(0.30)\end{array}$ & $\begin{array}{r}0.79 \\
(0.33)\end{array}$ & $\begin{array}{r}0.37 \\
(0.43)\end{array}$ \\
\hline Conflict & $\begin{array}{l}-0.17 \\
(1.40)\end{array}$ & $\begin{array}{r}0.22 \\
(1.54)\end{array}$ & $\begin{array}{l}-0.29 \\
(0.99)\end{array}$ & $\begin{array}{l}-0.75 \\
(0.53)\end{array}$ & $\begin{array}{r}-0.57 \\
(1.13)\end{array}$ \\
\hline Constant & $\begin{array}{r}1.99 \\
(1.67)\end{array}$ & $\begin{array}{r}3.84 \\
(2.91)\end{array}$ & $\begin{array}{r}6.64 \\
(2.59)\end{array}$ & $\begin{array}{r}6.89 \\
(0.33)\end{array}$ & $\begin{array}{r}-0.17 \\
(0.03)\end{array}$ \\
\hline $\begin{array}{l}N \\
\text { Adj. } R^{2} \\
p(\text { coeffs. zero })\end{array}$ & $\begin{array}{r}46 \\
0.597 \\
<0.001\end{array}$ & $\begin{array}{r}31 \\
0.486 \\
<0.001\end{array}$ & $\begin{array}{r}30 \\
-0.937 \\
0.005\end{array}$ & $\begin{array}{r}42 \\
-0.805 \\
0.051\end{array}$ & $\begin{array}{r}33 \\
0.239 \\
0.003\end{array}$ \\
\hline \multicolumn{6}{|c|}{$\begin{array}{l}\text { Dependent variable: } \\
\text { ln Physicians abroad/cap. }\end{array}$} \\
\hline Francophone & $\begin{array}{l}-0.69 \\
(2.11)\end{array}$ & $\begin{array}{l}-0.71 \\
(1.89)\end{array}$ & $\begin{array}{l}-0.69 \\
(2.55)\end{array}$ & $\begin{array}{l}-0.72 \\
(3.03)\end{array}$ & $\begin{array}{r}-0.98 \\
(3.11)\end{array}$ \\
\hline ln Land area & $\begin{array}{l}-0.18 \\
(2.84)\end{array}$ & $\begin{array}{l}-0.11 \\
(1.17)\end{array}$ & $\begin{array}{l}-0.03 \\
(0.54)\end{array}$ & $\begin{array}{l}-0.01 \\
(0.18)\end{array}$ & $\begin{array}{l}-0.13 \\
(2.33)\end{array}$ \\
\hline ln Physician wage abroad & $\begin{array}{r}0.20 \\
(0.13)\end{array}$ & $\begin{array}{l}-0.05 \\
(0.02)\end{array}$ & $\begin{array}{r}0.65 \\
(0.40)\end{array}$ & $\begin{array}{l}-1.75 \\
(1.87)\end{array}$ & $\begin{array}{r}-1.89 \\
(1.42)\end{array}$ \\
\hline ln Destination GDP/cap. & $\begin{array}{l}-0.11 \\
(0.10)\end{array}$ & $\begin{array}{l}-0.77 \\
(0.33)\end{array}$ & $\begin{array}{l}-1.66 \\
(0.99)\end{array}$ & $\begin{array}{r}0.70 \\
(1.10)\end{array}$ & $\begin{array}{r}1.42 \\
(1.63)\end{array}$ \\
\hline ln GDP/cap. & $\begin{array}{r}0.72 \\
(5.79)\end{array}$ & $\begin{array}{r}0.66 \\
(4.20)\end{array}$ & $\begin{array}{r}0.64 \\
(4.13)\end{array}$ & $\begin{array}{r}0.68 \\
(5.60)\end{array}$ & $\begin{array}{r}0.60 \\
(4.78)\end{array}$ \\
\hline Conflict & $\begin{array}{r}0.49 \\
(1.87)\end{array}$ & $\begin{array}{r}0.39 \\
(1.25)\end{array}$ & $\begin{array}{r}0.32 \\
(1.02)\end{array}$ & $\begin{array}{r}0.53 \\
(2.24)\end{array}$ & $\begin{array}{r}0.43 \\
(1.76)\end{array}$ \\
\hline Constant & $\begin{array}{l}-6.53 \\
(0.75)\end{array}$ & $\begin{array}{r}3.70 \\
(0.30)\end{array}$ & $\begin{array}{r}5.16 \\
(0.62)\end{array}$ & $\begin{array}{r}7.85 \\
(1.54)\end{array}$ & $\begin{array}{r}2.54 \\
(0.34)\end{array}$ \\
\hline$N$ & 45 & 31 & 30 & 42 & 32 \\
\hline Adj. $R^{2}$ & 0.589 & 0.475 & 0.436 & 0.503 & 0.657 \\
\hline$p$ (coeffs. zero) & $<0.001$ & $<0.001$ & $<0.001$ & $<0.001$ & $<0.001$ \\
\hline
\end{tabular}

Each column shows a single 3SLS regression. Absolute value of robust t-statistics in parentheses. 'Births attend.' is the percentage of deliveries attended by personnel trained to give the necessary supervision, care, and advice to women during pregnancy, labor, and the postpartum period; to conduct deliveries on their own; and to care for newborns. 'Diarr. prev.' is the percentage of children under age five with diarrhea requiring medical attention over a two-week period, and 'diarr. treat' is the percentage of those who received either oral rehydration therapy or increased fluids, with continued feeding. 'HIV prev.' is the percentage of people ages 15-49 who are infected with HIV, and 'HIV treat' is the percentage of adults with advanced HIV infection receiving antiretroviral treatment. 
Table 8: The relationship between emigrant stock and age at migration

Dependent variable: $\quad$ ln Physicians abroad/cap. ln Physician emigr./stock

Unweighted Weighted Unweighted Weighted

United States, census 2000: 614 physicians from 18 African countries

$\begin{array}{lllll}\text { Age at immigration } & -0.07 & 0.10 & -0.04 & -0.22\end{array}$

$N$

$\begin{array}{llrr}(1.65) & (0.94) & (1.49) & (1.84)\end{array}$

United States and Canada, survey 2006: 1,752 physicians from 31 African countries

$\begin{array}{lllll}\text { Age at immigration } & 0.01 & 0.08 & 0.00 & 0.03\end{array}$

$\begin{array}{rrrrr}N & 31 & 31 & 31 & 31\end{array}$

United States and Canada, survey 2006: 1,752 physicians from 31 African countries

$\begin{array}{lllll}\text { Migrated }>6 \text { yrs. before degree } & -0.63 & -3.37 & -0.29 & 0.75\end{array}$

$N$

$\begin{array}{llll}(1.27) & (2.95) \quad(0.80) \quad(0.73)\end{array}$

$\begin{array}{llll}31 & 31 & 31 & 31\end{array}$

France, census 1999: 2,664 physicians from 37 African countries
Age in 1999
$-0.01$
$-0.11$
(1.24)
(0.25)
37
37
0.01
$(0.46)$
$-0.04$
(0.81)

N

OLS regressions with absolute values of robust t-statistics in parentheses. All regressions include constant term, not reported. Columns 2 and 4 conduct the regressions with analytic weights in which the variance of each observation is inversely proportional to the number of census or survey observations used to generate the country-average used as the right-hand side variable. 


\section{A Appendix: Data sources}

\section{A.1 African physicians and professional nurses, abroad and domestic}

See Clemens and Pettersson (2006) for sources of the measures of health professionals abroad based on country of birth. The alternative 'mixed' measure of African physicians abroad, which focuses on country of training in measuring emigration to key receiving countries, comes from Bhargava and Docquier (2006).

\section{A.2 Domestic health worker stocks in receiving countries}

Physician and professional nurse stocks per 1,000 population in the United Kingdom, United States, Australia, Canada, and France in the year 2000 come from OECD Health Statistics 2006. These are multiplied by the population of each of those countries in 2000 (from the World Bank's World Development Indicators 2006) to get the total health professional stock in 2000. To calculate the number of physicians in Francophone Canada, the total number of Canadian physicians was multiplied by 27.7\% - the fraction of Canadian physicians who lived in Quebec in 1996, according to J. Roger Pitblado and Raymond W. Pong (1999), "Geographic Distribution of Physicians in Canada", Centre for Rural and Northern Health Research (Sudbury, Ontario: Laurentian University), page 3-8, Table 3.1. To calculate the number of professional nurses in Francophone Canada, the total number in Canada was multiplied by 25.2\% — which is the fraction of Canada's nurses living in Quebec in 2001 according to Canadian Institute for Health Information (2002), Supply and Distribution of Registered Nurses in Canada 2001 (Ottawa: CIHI), page 11. The total population of Francophone Canada is assumed to be that of Quebec (24.1\% of the Canadian population, according to the 2001 census of Canada) and Anglophone Canada is assumed to be the rest of the country.

\section{A.3 Health care and health outcomes}

Fraction of children 0-1 year vaccinated against measles 2001; infant mortality rate per 1,000 live births in 2000; child (under age 5) mortality in 2000 are from the World Bank Africa Database 2004 (Washington, DC: World Bank). Acute Respiratory Infection (ARI) prevalence (children under 5); ARI treatment (\% of children under 5 taken to a health provider); Births attended by skilled health staff (\% of total); Diarrhea prevalence ( $\%$ of children under 5); Diarrhea treatment ( $\%$ of children under 5 who received ORS packet); Immunization, DPT (\% of children ages 12-23 months); and Prevalence of HIV, total (\% of population aged 15-49) in 2000 are taken from World Development Indicators 2005 (Washington, DC: World Bank). Percentage of adults with advanced HIV infection receiving antiretroviral treatment are from WHO (2004), Investing in a Comprehensive Health Sector Response to HIV/AIDS (Geneva: World Health Organisation), Annex 1, pp 61-62 for Angola, Burundi, Burkina Faso, Botswana, Central African Republic, Côte d'Ivoire, Cameroon, Dem. Rep. Congo, Djibouti, Ethiopia, Ghana, Guinea, Kenya, Lesotho, Mozambique, Malawi, Namibia, Nigeria, Rwanda, Sudan, Somalia, Swaziland, Tanzania, Uganda, South Africa, Zambia, and Zimbabwe. They are taken from UNAIDS (2003), Progress Report on the Global Response to the HIV/AIDS Epidemic (Geneva: Joint United Nations Programme on HIV/AIDS), Annex 7, p. 90 for Benin, Eritrea, Gambia, Equatorial Guinea, Mauritius, Senegal, Sierra Leone, and Seychelles.

\section{A.4 Other development indicators}

GDP per capita (constant 2000 US $\$$ ) and primary school enrollment (\% gross) in 2000 are taken from World Development Indicators 2005 (Washington, DC: World Bank). Fraction of higher schooling complete in pop 15+, 1999 is taken from Robert Barro and Jong-Wha Lee (2000), "International Data on Educational Attainment Updates and Implications," Working Paper 7911 (Cambridge, MA: National Bureau of Economic Research). Land area in millions of square kilometers in 2001 comes from the World Bank Africa Database 2004 (Washington, DC: World Bank).

\section{A.5 Francophone countries}

The Francophone countries are defined as Algeria, Burundi, Benin, Burkina Faso, Central African Republic, Chad, Côte d'Ivoire, Congo (Rep.), Congo (Dem. Rep.), Comoros, Djibouti, Gabon, Guinea, Morocco, 
Madagascar, Mali, Mauritania, Niger, Rwanda, Senegal, and Tunisia. Note that Cameroon is not counted among these, due to the official policy of English/French bilingualism in place since 1961 (especially important in tertiary education).

\section{A.6 Conflict}

Armed conflict data come from the PRIO Armed Conflict Database, version 2.1, produced by the Centre for the Study of Civil War at the International Peace Research Institute, Oslo (PRIO) and the Department of Peace and Conflict Research, Uppsala University. The database is described in Nils Petter Gleditsch et al. (2002), "Armed Conflict 1946-2001: A New Dataset", Journal of Peace Research 39(5): 615-637, and in Håvard Strand et al. (2005), Armed Conflict Dataset Codebook, Version 3-2005 (Oslo: International Peace Research Institute [PRIO]). The conflict indicator takes the value "1" if there was an armed conflict of intensity 2 or 3 (on the PRIO scale of 1 to 3) in that country between 1970 and 1999, and " 0 " otherwise. An intensity of 2 or greater signifies more than 25 battle-related deaths per year and a total conflict history of more than 1000 battle-related deaths.

\section{A.7 Destination country economic conditions}

For each of the nine receiving countries, average annual general practitioner physician wage in PPP-adjusted US dollars was obtained from the ERI Salary Assessor international salary database, maintained by Baker, Thomsen Associates, a compensation and benefits consulting firm. This was used to create a weighted average destination-country physician salary for each sending country, weighted by the fraction of physicians born in that sending country and living abroad who live in that receiving country. The result is an index of the physician wage faced by the 'typical' physician emigrant from each sending country. An identical procedure created the professional nurse destination country wage index using Registered Nurse wages from Baker, Thomsen Associates. The destination-country GDP per capita index was constructed in a similar fashion, simply using exchange-rate GDP per capita in 2000 US $\$$ instead of wages - where the weights in the physician regressions are relative physician stocks abroad, and the weights are relative nurse stocks in the nurse regressions.

\section{A.8 Survey of African-born Physicians in the United States and Canada} See Clemens (2006).

\section{A.9 Census estimates of age and age at immigration of African-born physicians in the United States and France}

The census data on age and age at immigration for the analysis of African-born physicians in Table 8 were taken from anonymized microdata samples for the United States (5\% sample) and France (25\% sample):

United States: U.S. Dept. of Commerce, Bureau of the Census. Census of Population and Housing 2000 [United States]: Public Use Microdata Sample: 5-percent sample [Computer file]. ICPSR release. Washington, DC: U.S. Dept. of Commerce, Bureau of the Census [producer], 2003. Ann Arbor, MI: Interuniversity Consortium for Political and Social Research [distributor], 2003.

France: LASMAS Institut du Longitudinal and Centre National de la Recherche Scientifique, custom extract from Recensement de la Population : fichier détail au 1/4-France métropolitaine - 1999, prepared January 2006. 